\title{
Drivers of Past and Predicted Changes of Rainfall in and Around Mainland Southeast Asia
}

Nikolaos Skliris ( $\square$ N.Skliris@noc.soton.ac.uk)

University of Southampton https://orcid.org/0000-0002-2473-2586

Robert Marsh

University of Southampton

Ivan D. Haigh

University of Southampton

Melissa Wood

University of Southampton

Joel Hirschi

National Oceanography Centre

Stephen Darby

University of Southampton

Nguyen Phu Quynh

Southern Institute of Water Resources Research

Nguyen Nghia Hung

Southern Institute of Water Resources Research

\section{Research Article}

Keywords: Mainland South East Asia, Rainfall, Monsoon, Evaporation, Water Cycle, CMIP5

Posted Date: November 1st, 2021

DOI: https://doi.org/10.21203/rs.3.rs-194416/v2

License: () This work is licensed under a Creative Commons Attribution 4.0 International License. Read Full License 


\section{Abstract}

Observational rain gauge/satellite and reanalysis datasets since the 1950s are evaluated for trends in mean and extreme rainfall over Mainland Southeast Asia (MSEA). Rain gauge data indicate strong increases exceeding $50 \%$ in both annual mean precipitation and various extreme precipitation indices over Vietnam and the northwestern part of the peninsula since 1979. Increasing precipitation in MSEA is associated with increased monsoon intensity in southeast Asia and a northward shift of the monsoon activity centre towards MSEA over 1979-2018. Re-analysis data reveal warming-driven increases in evaporation over the seas adjacent to MSEA, including the main oceanic source regions feeding precipitation over the peninsula - the Arabian Sea, the Bay of Bengal, and the South China Sea. Furthermore, moisture budget analysis based on the ERA5 re-analysis also showed increasing oceanic moisture transport along the typical winter and summer moisture pathways towards the MSEA. However, the majority of the increased moisture from these oceanic sources ends up as summer precipitation over the oceanic regions adjacent to the MSEA. In contrast, the ERA5 data do reveal pronounced increases in winter precipitation over the MSEA, in accordance with rain-gauge data, that are associated with increased transport of moisture that originated from the western tropical Pacific and the South China Sea. Long-term amplification of the regional hydrological cycle is further investigated, through analysis of CMIP5 coupled climate models in historical and RCP4.5/8.5 21st century scenario simulations. The CMIP5 ensemble mean shows robust wide-spread trends in wet season precipitation with increasing frequency and intensity of extreme precipitation events over the MSEA, following strong increases in evaporation in the oceanic moisture sources.

\section{Introduction}

Coastal regions of MSEA (Fig. 1) are densely populated and highly exposed to flooding from coastal, fluvial and surface runoff sources. In Vietnam, $70 \%$ of the population lives in coastal regions, and around major deltas in particular. The Mekong delta, home of $19 \%$ of the population (18.6 million people) and the largest agricultural producing centre in the country (Dun, 2011), has been identified by the IPCC as being one of the three most vulnerable deltas in the world (Nicholls et al. 2007). Densely populated communities in the Mekong delta, most of which lie within $2 \mathrm{~m}$ of current mean sea level, are especially vulnerable to flooding, as a result of their exposure to storms and the annual monsoonal flood pulse. Here we focus on rainfall variability as a driver of flooding in MSEA.

Annual total rainfall in MSEA is dominated by the monsoon season, with occasional but major typhoon contributions on a synoptic timescale. The rainfall pattern is very complex and shows strong spatial and seasonal variability. The wind pattern is characterised by a well-established seasonal regime with winds and associated moisture transport mainly originating from the South China Sea and the western tropical Pacific during winter, and from the northern and western parts of the tropical Indian Ocean during summer (Sun and Wang 2015). Oceanic sources of moisture are known to provide the dominant contribution to precipitation over MSEA compared with continental moisture sources (Wu et al. 2012). There are also strong orographic constraints (see Fig. 1) which interact with the monsoon and the large-scale atmospheric circulation to shape local continental precipitation (Wang and Chang 2012), leading to pronounced spatial variations over MSEA. In particular large-scale mountain ranges in the western part of the peninsula between Myanmar and Thailand present an orographic meridional barrier that partitions rainfall east and west of the barrier (Tsai et al. 2015). Mountain ranges along much of Vietnam likewise present a meridional barrier that partly blocks westward moisture fluxes from penetrating further inland during winter and tropical storms that originate in the western Pacific during summer. The wet season across most of MSEA typically starts at mid-spring with the onset of the Southeast Asian summer monsoon and peaks in summer but as a consequence of combined orographic and seasonal wind patterns the wet season starts later and peaks in Autumn along the eastern part of the peninsula in Vietnam (Fig. 2). In the latter region, relatively strong precipitation persists even during winter, whereas in the rest of the peninsula precipitation levels are very low (Fig. 2d). At the northern border of MSEA, the Tibetan Plateau blocks winter cold events from the north, thereby generally confining the winter monsoon to southeastern Asia (Yanai and Wu 2006). 
The frequency and intensity of flooding events across the region are expected to increase as the hydrological cycle amplifies with anthropogenic global warming (Held and Soden, 2006). Observations and climate model simulations show that precipitation extremes intensify in a warming climate (e.g. O'Gorman 2015). The Clausius-Clapeyron relationship predicts an increase in the water holding capacity of air of approximately $7 \%$ per degree Celsius rise in temperature. Following energy and moisture balance constraints, the increased atmospheric moisture and its horizontal transport in the lower troposphere are expected to increase global mean precipitation and strengthen the mean evaporation minus precipitation pattern, with wet regions becoming wetter and dry regions becoming drier (Held and Soden, 2006). Satellite-derived observations over the global tropical ocean clearly show a robust tendency for a water cycle amplification under anthropogenic warming (Liu and Allan, 2012; Liu et al. 2012; Chou et al. 2013). Liu and Allan (2012), using multiple satellite-based observational products to analyse the response of the global tropical ocean precipitation intensity distribution to changes in surface temperature, found that the wetter area precipitation shows a robust response to temperature rise of around $20 \% / \mathrm{deg}$. K. A pronounced increase of tropical ocean rainfall over the last few decades is evidenced in several studies (Liu et al. 2012; Fasullo 2012; Skliris et al. 2014). As surface temperature rises, the largest increases in mean and extreme precipitation are expected in tropical regions of moisture convergence. Monsoon rainfall and extreme tropical storms in Southeast Asia are therefore at high risk of intensification, with potentially severe socio-economic implications for these regions.

Due to the highly sporadic and localised character of rainfall, and the large difficulties in obtaining reliable in-situ measurements of evaporation and precipitation, over the ocean in particular, there is a very high level of uncertainty in the estimation of observed variability and trends in surface freshwater fluxes (Hegerl et al. 2015). It is particularly difficult to assess drivers of long-term changes in regional continental-scale water cycling. This is especially the case in dynamically complex and data-sparse areas like the MSEA where local precipitation is strongly shaped by interactions between orography and large-scale, seasonally reversing, atmospheric circulation related to the monsoon, and which is also influenced by sporadic but strong storm events (typhoons) mainly originating in the Western Tropical Pacific. The interannual/decadal rainfall pattern is also strongly modulated by natural climate variability, with MSEA being located at the crossroads of the major coupled ocean/atmosphere variability modes of the tropical Pacific (El Nino Southern Oscillation) and Indian (Indian Ocean Dipole) Oceans.

Insights into changes in water cycling through time, and especially changes in moisture transport from ocean/land sources and moisture convergence over the MSEA, can be provided by Numerical Weather Prediction (NWP) model reanalyses and historical climate model simulations. However, atmospheric reanalyses have often been found to be unreliable for assessing long-term trends in the hydrological cycle over both land and ocean, violating basic physical constraints and being inconsistent with observational estimates (Trenberth et al. 2011; Skliris et al. 2014). There are also large discrepancies in the evolution of the global monsoon rainfall over land as estimated from various reanalyses, including contradictory and likely to be spurious trends both prior to and during the satellite era, as well as inconsistencies with moisture convergence estimated from the mass-corrected atmospheric moisture budget (Fasullo 2012).

Climate model historical simulations also show very large variations concerning changes in the hydrological cycle whilst they appear to underestimate surface freshwater flux and salinity responses to warming compared with observations (Durack et al. 2012; Zika et al. 2018; Skliris et al. 2020). Satellite-derived products have been shown to be more reliable tools to diagnose trends in precipitation (Fasullo 2012; Liu and Allan 2012). Although they also present uncertainties mainly arising from discontinuities in satellite data composition, with the inclusion of SSM/I data in 1987 presenting the major transition event (e.g. Schanze et al. 2010), there is a better consistency amongst satellite-derived precipitation products as compared to re-analyses (Liu and Allan 2012). Satellite-derived precipitation products, together with observationally constrained objectively analysed evaporation fields, seem to better diagnose hydrological cycle changes over the ocean compared with re-analyses (Schanze et al. 2010; Skliris et al. 2014; Skliris et al. 2020). Satellite-derived 
products are also shown to better diagnose trends in monsoon rainfall over land in a warming climate compared to reanalyses and climate models (Fasullo 2012).

CMIP5 simulations indicate a precipitation response to warming and precipitation trend in the wetter areas of tropical regions of $\sim 5 \% / \mathrm{deg}$. $\mathrm{K}$ and $0.6 \% /$ decade, respectively, over the recent historical period (Liu et al. 2012). However, these values were much lower compared to GPCP satellite-derived observations over the same regions at $~ 13-15 \% / \mathrm{K}$ and $2.4 \% /$ decade, respectively, suggesting that climate models largely underestimate the observed precipitation responses (Liu et al. 2012). One of the first climate model analyses for monsoon rainfall regions, based on the CMIP3 ensemble projections, showed a large increase in precipitation that was spatially coherent throughout MSEA and consistent amongst most climate models (Fasullo 2012). CMIP5 model projections also show a robust increase in Southeast Asia summer monsoon rainfall over the $21^{\text {st }}$ century, however there is a large inter-model spread for both intensity and the spatial pattern of change (Zhou et al 2019).

More recently, CMIP6 model simulations also reveal an accentuation of contrasts between wet and dry regions in the tropics/sub-tropics but with rainfall in wet regions increasing substantially more than decreasing in dry regions (Schurer et al. 2020). CMIP6 model projections also reproduce this strong enhancement of global land monsoon rainfall pattern with the largest rainfall increases being obtained in the Southeast Asian monsoon regions (Chen et al. 2020). However, the uncertainty of precipitation projections is still very high, for the long-term projections and the strongest emissions scenario in particular, with the large inter-model spread mainly being attributed to the model-dependent response to sea surface warming (Chen et al. 2020). Ge et al. (2019) investigated projected changes in precipitation extremes in Southeast Asia based on six high-resolution regional climate models and using the scenarios of $1.5^{\circ} \mathrm{C}$ and $2{ }^{\circ} \mathrm{C}$ global warming levels exceeding pre-industrial conditions. Their results showed that projected changes in various precipitation extreme indices were significantly amplified over the MSEA in both scenarios, while precipitation extremes were highly sensitive to the additional $0.5^{\circ} \mathrm{C}$ increase in global warming.

Our overall aim in this paper is to investigate large-scale coupled atmosphere/ocean processes that drive mean and extreme rainfall over and around the MSEA both in the past (1950 to present) and future (present to 2100). We do this using observationally-based (rain gauge and/or satellite-derived) and atmospheric model re-analysis data and using climate model projections. Our first objective is to assess historical long-term trends in mean and extreme precipitation over MSEA. Our second objective is to investigate links between changes in evaporation in oceanic moisture source regions and MSEA precipitation by performing a moisture budget analysis. Our third objective is to assess the impact of monsoon activity and large-scale natural climate variability modes of the tropical Indian and Western Pacific oceans on precipitation variations in and around MSEA. Our fourth objective is to examine future climatic trends in mean and extreme precipitation over MSEA and their link to ocean evaporation trends from CMIP5 coupled climate model $21^{\text {st }}$ century projections.

\section{Data And Models}

Three observationally-based (satellite-derived and/or gauge data) and two atmospheric re-analysis gridded precipitation datasets are used here to investigate precipitation variability and long-term trends over and around MSEA. The three observationally-based datasets comprise:

(1) The Global Precipitation Climatology Project (GPCP v2.3; https://psl.noaa.gov/data/gridded/data.gpcp.html), monthly mean data over land and ocean on a $2.5^{\circ} \times 2.5^{\circ}$ grid, available from 1979 , based on rain gauge observations over land and satellite retrievals (Adler et al. 2003);

(2) The Asian Precipitation - Highly-Resolved Observational Data Integration Towards Evaluation (APHRODITE), daily data spanning $1950-2007$ on a $0.25^{\circ} \times 0.25^{\circ}$ grid (Yatagai et al 2012; APHRO_MA-V1101, aphrodite.st.hirosaki-u.ac.jp); 
(3) Climate Prediction Centre (CPC), Global Unified Gauge-Based Analysis of Daily Precipitation

(https://psl.noaa.gov/data/gridded/data.cpc.globalprecip.html), daily data spanning $1979-2018$ on a $0.5^{\circ} \times 0.5^{\circ}$ grid.

The two atmospheric reanalysis-based evaporation and precipitation datasets used here are obtained from:

(1) NCEP/NCAR Reanalysis 1 (https://psl.noaa.gov/data/gridded/data.ncep.reanalysis.html) spanning 1948-present on a $2.5^{\circ} \times 2.5^{\circ}$ grid (Kistler et al. 2001) and

(2) The European Centre for Medium-Range Weather Forecasts ERA5 global reanalysis

(https://www.ecmwf.int/en/forecasts/datasets/reanalysis-datasets/era5) spanning 1979-present on a $0.25^{\circ} \times 0.25^{\circ} \mathrm{grid}$ (Hersbach et al. 2020). In addition, two variables provided in ERA5 involved in the moisture budget were used here, namely the vertically integrated atmospheric moisture transport convergence and the vertically integrated atmospheric water vapour transport.

Oceanic evaporation is also obtained by the Objectively Analyzed air-sea Fluxes (OAFlux) dataset developed by Yu et al. (2008) (http://rda.ucar.edu/datasets/ds260.1/), that blends NCEP and ERA-40 reanalysis products with satellite surface meteorology through an objective synthesis, with monthly data spanning 1958 -present on a $1^{\circ} \times 1^{\circ}$ grid. Near-surface salinity trends are assessed using the UK Met Office Hadley Centre Enhanced Ocean Data Assimilation and Climate prediction (ENACT) archive version4 (En4, subversion En4.1.1, $1^{\circ} \times 1^{\circ}$ grid) dataset

(http://www.metoffice.gov.uk/hadobs/en4) developed by Good et al. (2013).

We have chosen 6 sub-regions to investigate changes in precipitation over the MSEA, each of which is characterised by different precipitation/wind seasonal patterns and orographic constraints, namely: (1) South Vietnam, (2) North Vietnam, (3) Central MSEA, (4) North MSEA, (5) South Myanmar, and (6) North Myanmar (see Fig. 1). For simplicity, rectilinear boxes are used to define the 6 sub-regions. Note that the geographical areas of sub-regions named by a specific country largely consist of that country (or the largest part of that country) but may also include smaller portions from other nations.

Following the atmospheric backtracking analysis of continental precipitation by Van der Ent et al. (2013) we have identified three major oceanic regions supplying moisture for MSEA precipitation, namely: The South China Sea, the Bay of Bengal, and the Arabian Sea. A significant oceanic moisture source is defined when on average more than $20 \%$ of the total evaporation, and at least $250 \mathrm{~mm}_{\text {year }}^{-1}$ of evaporation from the source region, ends up as continental precipitation (Van der Ent et al. 2013). Area-averaged monthly evaporation timeseries are constructed for each oceanic region.

In order to investigate future changes in mean precipitation and precipitation extremes over MSEA we analysed the output of the historical, and Representative Concentration Pathways 4.5 (RCP4.5) and 8.5 (RCP8.5) simulations from 33 Coupled Model Intercomparison Project Phase 5 (CMIP5) models (Taylor et al. 2012), including ACCESS1-0, ACCESS1-3, bcc-csm1-1, BNU-ESM, CanESM2, CCSM4, CESM1-BGC, CESM1-CAM5, CMCC-CM, CNRM-CM5, CSIRO-Mk3-6-0, ECEARTH, FGOALS-g2 FIO-ESM, GFDL-CM3, GFDL-ESM2G, GFDL-ESM2M, GISS-E2-H, GISS-E2-R, HadGEM2-CC, HadGEM2ES, inmcm4, IPSL-CM5A-LR, IPSL-CM5A-MR,

IPSL-CM5B-LR, MIROC5, MIROC-ESM, MIROC-ESM-CHEM, MPI-ESM-LR, MPI-ESM-MR, MRI-CGCM3,NorESM1-M, and NorESM1-ME. The periods analysed include 1861-2005 for the historical simulations, and 2006-2100 for the RCP4.5 and RCP8.5 simulations.

We constructed ensemble mean monthly timeseries of evaporation (for the three oceanic moisture source regions) and precipitation (for MSEA and the six MSEA sub-regions). We use extreme precipitation indices based on daily precipitation data for both observations (CPC) and CMIP5 outputs as defined by the Expert Team on Climate Change Detection and Indices (ETCCDI) to quantify climate extremes with reoccurrence times of a year or shorter (Sillmann et al. 2013a).

Page 5/39 
Extreme precipitation indices employed here include RCPTOT (total precipitation of wet days), SDII (simple daily precipitation intensity), R10mm (number of days of heavy rainfall, defined as $>10 \mathrm{~mm} /$ day), R20mm (number of days of very heavy rainfall, defined as $>20 \mathrm{~mm} /$ day), and CDD (number of consecutive dry days). Wet days are defined as days with $>1 \mathrm{~mm}$ of rainfall. The annual extremes of the daily CMIP5 data have been obtained from the ETCCDI extremes indices archive at the Canadian Centre for Climate Modelling and Analysis (https://climatemodelling.canada.ca/data/climdex/climdex.shtml).

We construct monthly anomaly time series for all datasets by subtracting the climatological monthly mean from the monthly data at each grid point. Seasonal and annual anomalies are then constructed from the monthly anomalies, allowing us to compute linear trends for both the observational and CMIP5 historical (1860-2005), and the RCP4.5/8.5 (2006-2100) time-series. Uncertainties in linear trends are estimated using the standard error of a linear fit (least squares).

\section{Results And Discussion}

In the following, we first outline historic precipitation and oceanic evaporation trends in the region. We then focus on the atmospheric moisture budget, and changes thereof, distinguishing between changes in winter and summer, and we investigate the link between changes in oceanic evaporation and changes in precipitation in and around the MSEA. Moreover, we explore the association of MSEA precipitation changes to the monsoon and leading modes of climate variability in the region. Finally, we analyse projected changes of mean and extreme MSEA precipitation through the $21^{\text {st }}$ century.

\subsection{Long-term historic trends in mean and extreme precipitation over MSEA}

Land precipitation based on the rain-gauge-based APHRODITE dataset, analysed here to assess long-term trends, show an overall increase in precipitation since the 1950s but there is no coherent spatial signal over MSEA. There is a statistically significant (at the $95 \%$ confidence interval) increase in annual precipitation ( 30-40\% in respect to climatological annual mean over 1950-2007) throughout Vietnam (sub-regions 1 and 2) and decreasing trends in North Myanmar (sub-region 6) throughout the wet season, with maximum changes during summer (Fig. 3). On the other hand, there are very low trends (not statistically significant) in large parts of north and central parts of MSEA including in South Myanmar and Thailand, in agreement with the study of Tsai et al. (2015).

Analysis of precipitation data from the NCEP/NCAR reanalysis over 1950-2018 shows a statistically significant positive trend only over southern MSEA ( 20-30\% increase with respect to the climatological annual mean) with a more widespread signal compared to the rain gauge dataset and low (not statistically significant) trends roughly north of $15^{\circ}$ North (Fig. 4). In general, there are large spatial discrepancies between the two datasets in representing long-term trends, over the northwest MSEA in particular. Moreover, the trend in land precipitation in NCEP/NCAR re-analysis is much less than that over the ocean around MSEA. Both NCEP/NCAR and $20^{\text {th }}$ Century reanalysis products suggest a strong large-scale increase in precipitation in the eastern tropical Indian Ocean and western tropical Pacific Ocean over that period (Skliris et al. 2014). This large-scale, spatially-coherent, pattern of increasing oceanic precipitation since the 1950s appears to be the most pronounced signal of change within the global ocean.

Spatial patterns in precipitation trends over 1979-2018 as derived by the CPC rain gauge-based dataset show spatially variable changes, with larger precipitation increases exceeding $50 \%$ (with respect to the climatological mean) over Vietnam (Sub-regions 1 and 2) and the northwestern part of the peninsula (sub-region 6)), versus much lower trends, or even precipitation decreases, over large parts of central and northern MSEA. Seasonal precipitation trend patterns (Fig. 5 and Table 1) indicate that this contrast is evidenced throughout the summer monsoon season (Fig. 5a), but it is also present in the declining phase of the monsoon in autumn (Fig. 5c). A pronounced widespread increasing precipitation trend persists along the Vietnam coast in winter (Fig. 5d).

Page 6/39 
Importantly, the daily CPC data clearly demonstrate an intensification of extreme precipitation events over 1979-2018 with highly statistically significant positive trends in several extreme precipitation indices considered here throughout Vietnam (sub-regions 1 and 2) and the northwestern part of the peninsula, in North Myanmar (sub-region 6) in particular

(Fig. 6 and Table 2). Increases in total wet season precipitation (PRCPTOT) and in number of days of heavy (R10mm) and extreme (R20mm) rainfall exceed $50 \%$ in the above areas over 1979-2018. There is also a significant decrease in the dry season period throughout Vietnam (Fig. 6d). On the other hand, together with mean summer precipitation, extreme precipitation indices are significantly reduced over parts of Cambodia, Thailand, and Laos over 1979-2018.

Analysis of satellite-derived ocean precipitation (Fig. 7a) and near-surface salinity (Fig. 7c) show that ocean precipitation has increased and salinity decreased, respectively, around MSEA over the last 40 years (1979-2018) indicating an accelerated broad-scale freshening of the tropical eastern Indian and western Pacific oceans over that period (Skliris et al. 2014). Low-resolution GPCP show a statistically significant positive trend over southern MSEA but is largely inconsistent with the $\mathrm{CPC}$ rain-gauge dataset (Fig. $7 \mathrm{~b}$ ) in terms of the identification of precipitation trends over large parts of the peninsula, in northwestern MSEA in particular.

Rain-gauge data (Aphrodite and CPC) indicate a strong widespread precipitation increase throughout Vietnam since the 1950 's which has accelerated over the last 40 years. This pronounced change in precipitation obtained here is in contrast with the study of Nguyen et al. (2014), who investigated variations of Vietnam rainfall based on 60 meteorological stations over the earlier period of 1971 to 2010 but found no statistically significant trends over most of the Vietnam region. However, in a more recent study Gao et al. (2019) found a strong significant increase in spring precipitation with a concomitant decrease in extreme drought throughout Vietnam during the past 4 decades, in agreement with our results.

\subsection{Long-term changes in evaporation over oceanic moisture sources}

Here we investigate evaporation changes in the main oceanic sources of moisture for MSEA as defined in Van der Ent et al. (2013): (1) the South China Sea, (2) the Bay of Bengal, and, (3) the Arabian Sea. Seasonal surface wind patterns clearly reveal a reversing source of moisture fluxes to MSEA from the South China Sea in winter, to the Bay of Bengal in summer (Zhang et al. 2019). Figure 8 shows the climatological mean field of vertically averaged atmospheric water vapour transport in the tropical Indian Ocean during winter and summer, respectively, from the ERA5 re-analysis.

There are two distinct major oceanic moisture pathways providing moisture for precipitation to MSEA following the seasonal wind pattern regimes. During summer moisture transport gains intensity in a northeastward pathway along the highly evaporative northwestern Indian Ocean and Arabian Sea, then eastward through and south of the Indian Peninsula to the Bay of Bengal to finally reach the MSEA. During winter the moisture transport direction is reversed from eastward to westward with ocean moisture sources located in the northwestern Pacific Ocean and the South China Sea. Moisture transport towards the MSEA is considerably decreased during winter with relatively large values being obtained only in the South China Sea and across the southern part of the MSEA. Continental moisture transport, mainly reaching the northern part of the peninsula, is several times lower than oceanic moisture transport, throughout the year.

The Bay of Bengal moisture contribution for MSEA precipitation peaks in June-August with the summer monsoon peak mainly supplying moisture in the northwestern part of the peninsula where on average it contributes locally to 10-25\% of total precipitation (Van der Ent et al. 2013). The South China Sea moisture contribution peaks in August-November mainly supplying moisture to the east coast along Vietnam, when the monsoon period is in the declining phase, contributing to $10-25 \%$ of total precipitation (Van der Ent et al. 2013). The Arabian Sea, although relatively distant, is also a significant moisture source, mainly supplying moisture to northwestern MSEA where on average it contributes to 10$20 \%$ of total precipitation. 
Figure 9 shows the spatial pattern of long-term trends in evaporation since the 1950s from NCEP/NCAR (1950-2018) and OAFlux (1958-2018). Both products indicate broad-scale evaporation increases in oceanic moisture sources in the northwestern Indian Ocean (including the Bay of Bengal and the Arabian Sea) and the South China Sea supplying moisture to MSEA. Our analysis of area-averaged ocean evaporation based on the OAFlux dataset (Fig. 10) shows highly statistically significant positive trends over the Arabian Sea $(0.085 \mathrm{~mm} / \mathrm{day} / \mathrm{decade})$, Bay of Bengal (0.069 $\mathrm{mm} /$ day/decade), and South China Sea ( $0.096 \mathrm{~mm} /$ day/decade), amounting to increases of annual evaporation of $13 \%$, $10 \%$, and $16 \%$, respectively, during 1958-2018. The long-term evaporation increases obtained here in the oceanic moisture sources for MSEA precipitation are in-line with increasing surface warming (not shown) that would act to enhance ocean latent heat fluxes in these regions. This trend seems to be part of a broad-scale spatially coherent pattern of evaporation increase in the tropical Indian and western Pacific Oceans that is consistent with a warming-driven intensification of the global hydrological cycle, clearly evidenced over the last 50-60 years (Durack et al. 2012; Skliris et al. 2016; Zika et al. 2018).

OAFlux evaporation analysis also shows that evaporation trends become stronger over 1979-2018 in the main three moisture source regions (Arabian Sea: $0.123 \mathrm{~mm} /$ day/decade; Bay of Bengal: $0.088 \mathrm{~mm} /$ day/decade; South China Sea: $0.126 \mathrm{~mm} /$ day/decade) as ocean surface warming is accelerating. Area-averaged evaporation and SST anomalies are significantly correlated in all three regions $(R \sim 0.6-0.7, p<0.05)$, as is consistent with the study of Su and Feng (2015) who found a significant positive broad-scale warming-driven linear trend in evaporation in the Tropical Indian Ocean over 1979-2011 based on the analysis of various atmospheric re-analysis products.

Accelerating precipitation trends over large parts of MSEA after 1979 coincide with increasing trends in evaporation in all three of the major oceanic moisture sources. The higher rate of evaporation increase between ocean moisture source regions is obtained in the South China Sea, which could be associated with the large increasing precipitation trend over the eastern coast of the peninsula along the whole Vietnam region. This is especially evidenced during autumn and winter when moisture fluxes to Vietnam originate mainly from the South China Sea. On the other hand, moisture transport from the Bay of Bengal and Arabian Sea mainly affect the northwest part of MSEA during summer. Therefore, evaporation increases in these two oceanic moisture source regions could explain at least part of the pronounced precipitation increases over NW MSEA and North Myanmar.

As expected, correlations between seasonal area-averaged evaporation in the ocean moisture source regions (OAFlux) and precipitation (CPC) over MSEA sub-regions are generally low and not statistically significant. This is because the climatological mean contribution of each of the three ocean source regions to total precipitation of each sub-region is relatively small (varying between roughly 5 and 30\%, Van der Ent et al. 2013). Statistically significant correlations ( $R \sim 0.3$ ) were only found in this study between precipitation in Vietnam regions and South China Sea evaporation during the autumn and winter. On the other hand, large parts of central and north MSEA show small and not statistically significant trends in precipitation, whereas there are even statistically significant negative trends in summer and autumn over most of Cambodia and parts of southern Thailand and Laos (see Fig. 5). Orographic constraints, i.e. meridional mountain ranges along Vietnam and western Thailand blocking eastward and westward moisture transport, respectively, together with changes in local moisture convergence, could explain why these increased ocean moisture signals may not reach the interior of the peninsula to enhance precipitation in central MSEA.

In general, therefore, continental precipitation increases observed over parts of the MSEA cannot be attributed to increases in oceanic evaporation in the moisture source regions because long-term changes in the other components of the moisture budget (such as moisture transport and local moisture convergence/recycling) are difficult to be assessed from observations. Although oceanic sources of moisture contribute considerably more than continental sources to precipitation over MSEA, it is very difficult to assess the contribution of land moisture changes to the local precipitation trend. There is currently large uncertainty in estimating global evapotranspiration trends (Zhang et al., 2016; Pan et al., 
2020). Ensemble mean global datasets based on advance remote sensing and land surface models indicate much lower and mostly not statistically significant evapotranspiration trends over MSEA compared to oceanic evaporation trends during recent decades (Pan et al. 2020).

\subsection{Water cycle and moisture budget changes in ERA5}

In this sub-section we further explore the high-resolution ERA5 re-analysis dataset (1979-2018) to investigate long-term changes in the water cycle components over the ocean and the MSEA. We also perform a moisture budget analysis for the ocean moisture source regions and the MSEA to investigate the link between changes in oceanic evaporation and changes in precipitation in and around the MSEA.

\subsubsection{Annual trends in water cycle components and water vapour transports}

Figure 11 shows annual trends in the water cycle components $(E, P$, and $E-P)$ as well as the vertically integrated atmospheric water vapour transport in ERA5 over 1979-2018. These results show a broad-scale increasing annual evaporation trend in the tropical Indian Ocean (Fig. 11a), in agreement with the other ocean evaporation datasets considered here (OAFlux and NCEP/NCAR) and also consistent with the study of Su and Feng (2015), based on a large number of atmospheric re-analysis products. However, overall, oceanic evaporation trends are less pronounced in ERA5 as compared to the objectively analysed OAFlux dataset over 1979-2018. Annual and seasonal trends in ERA5 land evaporation (evapotranspiration) are too small compared to oceanic evaporation trends ( one order of magnitude lower) and not statistically significant in the largest part of the MSEA over the considered period. This is consistent with recent studies showing very low/insignificant evapotranspiration trends over MSEA during the last few decades (Zhang et al., 2016; Pan et al., 2020). Importantly, evapotranspiration was found not to be correlated to local precipitation over MSEA (Zhang et al. 2016), indicating a very low contribution to moisture budget variations.

The spatial pattern of the annual trend in vertically-averaged atmospheric water vapour transport shows significant increases along the two main seasonal pathways of ocean moisture feeding the MSEA (Fig. 11b). Together with extra moisture reaching the North Indian Ocean from the equatorial region and the northwestern tropical Pacific, net evaporation $(E-P)$ is strongly increasing in large parts of the southern Arabian Sea, in the northeastern equatorial zone (south of the Bay of Bengal) and in the central South China Sea providing extra moisture along the main moisture pathways to the MSEA (Fig. 11d). This leads to a strong increase in annual precipitation around the MSEA (Fig. 11c) and especially in the Bay of Bengal, which seems to have been receiving a large part of this extra moisture.

ERA5 shows a widespread increase in annual precipitation over the Bay of Bengal that is consistent with the satellitederived GPCP data. However, area-averaged annual precipitation increase over the Bay of Bengal is lower in ERA5 ( 18\%) compared to GPCP (28\%) over 1979-2018. Results indicate an amplification of the oceanic water cycle over the tropical Indian Ocean during 1979-2018 with increasing oceanic moisture transports, whilst dry regions such as the Arabian Sea $(E>P)$ are becoming drier $(\Delta E>\Delta P)$ and wet regions such as the Bay of Bengal $(P>E)$ are becoming wetter $(\Delta P>\Delta E)$.

Spatial patterns of precipitation trends since 1979 in southeast Asia show a relatively good consistency between reanalyses (NCEP/NCAR, ERA5) and satellite-derived precipitation (GPCP) over the ocean (see Fig. 7a), but much larger discrepancies over land. ERA5 precipitation trends over MSEA are consistent in sign over some parts of the peninsula, but much lower in magnitude compared with the CPC rain-gauge data over 1979-2018 (see fig. 7b). In particular, relatively low and mostly not statistically significant precipitation increases are obtained over the western part of MSEA and close to the Vietnamese coastline whereas decreasing trends are obtained in central and northern parts of the peninsula. ERA5 precipitation trend spatial pattern is inconsistent across Vietnam and North Myanmar with rain-gauge data, which show instead large widespread precipitation increases. Area-averaged annual precipitation over South MSEA $\left(5-18^{\circ} \mathrm{N}\right)$ is 
increased by $\sim 6 \%$ in ERA5 compared to $\sim 26 \%$ in CPC. The discrepancy is even larger over North MSEA $\left(18-30^{\circ} \mathrm{N}\right)$ where ERA5 shows a decrease in annual precipitation of $\sim 13 \%$ compared to an increase in annual precipitation in CPC of $\sim 20 \%$.

\subsubsection{Moisture budget changes over summer and winter}

Here we focus on long-term changes of the moisture budget over winter and summer seasons which are characterised by contrasting wind/moisture transport regimes. We calculated the spatial change patterns (1979-2018) of $P$, E-P, verticallyintegrated moisture transport convergence, and vertically-integrated atmospheric water vapour transport during summer (Fig. 12) and winter (Fig. 13). We also performed an area-averaged moisture budget analysis for the south and north parts of the MSEA as well as for four oceanic moisture source regions, including the three major regions discussed in the previous sections (Arabian Sea, Bay of Bengal, and South China Sea) and the northeast equatorial region which is identified here as another major moisture source region for precipitation in and around the MSEA. We calculated areaaveraged $E, P$, and $E$-P change over each region as well as changes in the zonally/meridionally integrated atmospheric water vapour transports across the boundaries of each region, with results summarized in Figure 14.

In a steady state, the seasonal mean local precipitation minus evaporation $(P-E)$ field averaged over a specific region is roughly balanced by the vertically-integrated moisture transport convergence over this region (Brubacker et al. 1993; Wang et al. 2017). The moisture budget is expressed as follows (Wang et al., 2017):

$\bar{P}-\bar{E}=-\frac{1}{g} \overline{\nabla \cdot \int_{p_{s}}^{p_{t}} q \vec{V} d p}$

where $P$ is the precipitation, $E$ is the evaporation, $q$ is the specific humidity, and $\vec{V}$ is the horizontal wind vector, $p_{t}$ and $p_{s}$ are pressure at the surface and top level of the atmospheric column, respectively, and the overbars denote seasonal means. In a transitioning state, long-term changes in $P-E$ are expected to follow changes in the moisture transport convergence over this region.

During summer, results show a strong increase in moisture transport roughly all along the main northeastward moisture pathway from the western equatorial region to the Arabian Sea (Fig. 12a). Extra moisture is imported over the Arabian Sea from the western equatorial region with the northward moisture transport at the southern (equatorial) boundary of the Arabian Sea increasing by $~ 5 \%$ during summer (Fig. 14a). As expected, the spatial change pattern of moisture transport convergence (Fig, 12b) strongly resembles that of $P$-E (Fig 12d).

Moisture divergence is significantly increasing in large parts of the Arabian Sea indicating an increase in moisture export of this region with summer net evaporation over the Arabian Sea increasing by 27\% (Fig. 14a). Moisture export is increasing along the eastern (continental) boundary of the Arabian Sea except from the northern part where moisture export decreases resulting in a relatively small increase in the total eastward transport of $\sim 3 \%$ across the eastern continental boundary towards the India Peninsula.

A strong increase in moisture export is obtained in the southeastern oceanic boundary of the Arabian Sea where the (southward) moisture transport increases by $~ 80 \%$. Moisture transport continues to increase as moisture enriched air masses from the Arabian Sea circulate around the Indian Peninsula and over the northeast equatorial zone. In the latter region a pronounced decrease in moisture convergence occurs. Increasing moisture export from this region following its eastward moisture pathway feeds a large moisture import to the Bay of Bengal with moisture (northward) transport increasing by $\sim 12 \%$ in its southern boundary over 1979-2018. 
On the other hand, there is a small (and not statistically significant) decrease in the eastward moisture transport from the Indian Peninsula to the Bay of Bengal. Moisture (northeastward) transport towards the MSEA increases in the southern part and decreases in the northern part of the Bay of Bengal. A large part of the increased moisture input converges within the southern part of the Bay of Bengal leading to a pronounced increase in precipitation there (Fig. 12d). However, although moisture transport increases towards the south part of the MSEA (roughly south of $18^{\circ} \mathrm{N}$ ), moisture convergence decreases in most parts of the peninsula.

Increases in summer precipitation are obtained only along the western part of the peninsula but are relatively small and mostly not statistically significant whereas there are decreases in precipitation over the eastern part of the peninsula resulting in a low negative (and not significant) trend averaged over south MSEA (Fig. 14a). Results show a significant negative trend in area-averaged precipitation over north MSEA $\left(18-30^{\circ} \mathrm{N}\right)$ of $\sim 13 \%$ (Fig. 14a) associated with strongly decreasing continental moisture transport and moisture convergence across the region (Fig. 12a, b).

During winter, ERA5 data reveal a pronounced precipitation trend in and around MSEA (Fig. 13d) in accordance with the observationally-based datasets considered here (GPCP over the ocean and CPC over land). This widespread precipitation trend is clearly associated with strongly increasing westward transport of moisture originated from the northwestern tropical Pacific Ocean and the South China Sea (Fig. 13a). Winter westward moisture transport integrated over the eastern and western boundaries of the South China Sea is largely increased i.e. by 35\% and 45\% (with respect to the climatological winter mean), respectively, over 1979-2018 (Fig. 14b). Moreover, the core of maximum moisture transport area, typically obtained in the southern part of the peninsula, is shifted northward covering a larger part of the MSEA resulting in exceptionally high rainfall, especially over the Vietnamese coast.

In the south part of MSEA $\left(5-18^{\circ} \mathrm{N}\right)$ there is pronounced rainfall increase during winter of $~ 80 \%$ over 1979-2018 (Fig. 14b). However, the extra moisture is mainly converged close to the coastline with much lower rainfall increases over the peninsula interior. In contrast there is a small but statistically significant decrease in rainfall of $\sim 15 \%$ over the northern part of the peninsula associated with decreasing moisture (eastward) transport over the continent and the northern part of the Bay of Bengal. CPC data show a similar trend pattern during winter over the same period (1979-2018), with a pronounced rainfall increase $(\sim 80 \%)$ in the south part of MSEA, but very low and not statistically significant trends in the northern part of the peninsula. This large increase in winter moisture transport across the eastern coasts of MSEA may also explain the large decrease of the dry season duration across Vietnam, as evidenced by the large reduction in the CDD index there (see fig. 6).

Our analysis demonstrates that re-analysis products are quite consistent with observationally-based products in estimating water cycle changes over the ocean but there is much less coherency regarding changes over land. Long-term trends in oceanic evaporation from re-analyses and objectively-analysed datasets show a good level of agreement with all products indicating large increases in evaporation over the tropical Indian Ocean over the last 40 years. Similarly, some coherency in the precipitation spatial change patterns over the ocean is evident between ERA5 and the satellitederived GPCP dataset, although ERA5 generally underestimates the intensity of precipitation trends. There is also a relatively good agreement between ERA5 and CPC precipitation spatial change patterns over MSEA during winter. ERA5 reveals a pronounced increase in the transport of moisture from South China Sea and the western tropical Pacific during winter which drives large widespread increases in precipitation over MSEA, a pattern that it is also evident in the raingauge data (CPC).

On the other hand, there are large discrepancies in precipitation changes over land during the summer period. ERA5 shows relatively low, and in some regions even opposing trends in precipitation compared to observationally-based datasets (CPC and GPCP). Although eastward oceanic moisture transport towards the MSEA increases during summer, moisture convergence decreases over a large part of the MSEA in ERA5. The majority of the additional oceanic moisture produced over the last 40 years ends up as precipitation over the adjacent oceanic regions, in the Bay of Bengal in 
particular, with vary small changes in moisture transport and continental precipitation over the MSEA. Given that evapotranspiration trends are very small this pattern is inconsistent with the observational datasets which indicate instead widespread increases in moisture convergence across Vietnam and North Myanmar.

\subsection{Impacts of Monsoon and natural modes of climatic variability on precipitation changes over MSEA}

The Monsoon is the major climatic driver controlling precipitation over MSEA, especially during the summer period. The South Asian Summer Monsoon is mainly induced by the land-sea thermal contrast which drives large ocean moisture transport to MSEA (Wu et al. 2012). However, typical indices used to investigate monsoon activity in Southeast Asia, such as the Western North Pacific-East Asian monsoon Index (WNPEA) and the Indian Monsoon Index (IMI), show low correlations to MSEA precipitation (Tsai et al. 2015). Here we use the Summer Asian Monsoon Outgoing Longwave Radiation (OLR) index (SAMOI-A; http://ds.data.jma.go.jp/tcc/tcc/products/clisys/emi.html) to investigate changes in the Monsoon intensity over the study area. SAMOI-A consists of reversed-sign area-averaged OLR anomalies for the area from the Bay of Bengal to the east of the Philippines (averaged over May-October and normalized by the standard deviation).

OLR is often used as a proxy for convection in tropical regions with lower values of OLR indicating more enhanced convective activity under cloudy conditions. Positive and negative SAMOI-A values indicate enhanced and suppressed summer monsoon activity, respectively. The spatial pattern of SAMOI-A is roughly centred over the MSEA and Indonesian Seas, enabling us to better capture changes in monsoon activity in this region over summer and early autumn. The correlation pattern between SAMOI-A and summer precipitation in Southeast Asia (Fig. 15a) show positive correlations across MSEA (R 0.4-0.6) with maximum correlations along the Vietnam coast (R 0.6-0.7).

In addition, the SAMOI-N index is used to investigate meridional shifts of the active convection area associated with the monsoon. The correlation pattern between SAMOI-N and precipitation shows a dipole with increasing precipitation over North MSEA and decreasing precipitation over the Indonesian Seas with maximum positive correlations $(\mathrm{R} \sim 0.5-0.6)$ obtained in the northwestern part of the peninsula (Fig. 15c). SAMOI-A significantly increases during 1979-2018 (Figure $15 b)$ indicating increasing summer monsoon intensity over MSEA during that period that is consistent with the large increase in summer precipitation over MSEA evidenced in the rain-gauge data. Moreover, the SAMOI-N index also increases over the same period (Fig. 15d) revealing a northward shift of the monsoon centre towards northern MSEA, further enhancing Monsoon intensity there.

Precipitation over MSEA is also associated with the major modes of natural climate variability of the tropical Pacific and Indian Oceans. One of the key challenging issues regarding the changing hydrological cycle is how to distinguish between natural low-frequency modes of large-scale variability and long-term climatic trends, and hence to properly attribute changes in the hydrological cycle to either natural variability or anthropogenic forcing. In particular, the signal of the El Nino Southern Oscillation (ENSO) is imprinted in the changing spatial patterns of long-term surface freshwater flux and salinity in the tropical Pacific and Indian oceans and may skew possible anthropogenic climatic trends (Skliris et al. 2014).

Rainfall over the Southeast Asian seas has strong positive correlations to a la Nina-like SST anomaly pattern (Caesar et al. 2011; Skliris et al. 2014). The Southern Oscillation Index (SOl;

https://www.ncdc.noaa.gov/teleconnections/enso/indicators/soi), which measures the intensity of ENSO with strongly positive (negative) values indicating a La Nina (El Nino) event, is significantly correlated with annual precipitation over the Western tropical Pacific (R 0.5-0.8) as well as over MSEA (R 0.4-0.5) (Fig. 16a). SOI significantly increases (more La Nina events) over the last 40 years (Fig. 16b) which may partially explain the strong large-scale precipitation increase around MSEA, in the western tropical Pacific and northeastern tropical Indian oceans (see fig. 3). The observed ocean

Page 12/39 
precipitation increase around MSEA is concomitant and consistent with broad-scale decreasing ocean surface salinity over the same period (Skliris et al. 2014).

The two dominant modes of tropical Indian Ocean variability, namely the Indian Ocean Basin Mode (IOBM) and the Indian Ocean Dipole (IOD), also control climate conditions and local continental precipitation in many regions surrounding the tropical Indian Ocean. The IOBM features inter-annual basin-wide warming/cooling in the Tropical Indian Ocean and is closely associated with ENSO (Klein et al. 1999). The IOBM index is defined as the SST anomaly averaged over the tropical Indian Ocean $\left(40^{\circ} \mathrm{E}-100^{\circ} \mathrm{E}, 20^{\circ} \mathrm{S}-20^{\circ} \mathrm{N}\right)$. Inter-decadal variations of IOBM show a strong positive increase since the 1950s (Huang et al. 2019). A positive IOBM index, typically peaking in spring, is associated with increasing (decreasing) summer precipitation over North (South) MSEA although correlations are relatively low (Zhang et al. 2019).

Low and statistically insignificant correlations were found here between seasonal patterns of precipitation and IOBM in most of the MSEA. On the other hand, the correlation pattern between detrended IOBM and evaporation (Fig. 17a) shows positive statistically significant correlations across the tropical North Indian Ocean (R 0.4-0.5) including the main ocean moisture source regions for MSEA precipitation. Increasing (positive) IOBM over recent decades (Fig. 17b) is associated with anomalous surface warming in the tropical Indian ocean. In addition, the centre of action in the IOBM shifted from the Southeast Indian Ocean towards the Arabian Sea after the late 1970s (Sun et al. 2018). Roxy et al. (2014) identified fastest long-term warming in the Western Indian Ocean (WIO, 50-65 $5^{\circ}, 5^{\circ} \mathrm{S}-10^{\circ} \mathrm{N}$ ) during Northern Hemisphere summer months, compared with slower warming across the rest of Indian Ocean $\left(70-100^{\circ} \mathrm{E}, 20^{\circ} \mathrm{S}-20^{\circ} \mathrm{N}\right)$. Higher positive SST anomalies are observed in the oceanic moisture sources including the Arabian Sea and Bay of Bengal (Sun et al. 2018), which may have driven the large increases in evaporation evidenced in this study, suggesting that there was potentially an increased supply of ocean moisture for MSEA precipitation over that period.

The Indian Ocean Dipole (IOD) mode is characterised by a strong east-west sea surface temperature gradient with cold anomalies off Sumatra and warm anomalies in the western Indian Ocean, accompanying wind and precipitation anomalies (Saji et al. 1999). The impact of IOD on MSEA precipitation is investigated here using the Dipole Mode Index (DMI) measuring the SST anomaly difference between the western $\left(10^{\circ} \mathrm{S}-10^{\circ} \mathrm{N}, 50^{\circ} \mathrm{E}-70^{\circ} \mathrm{E}\right)$ and the eastern $\left(10^{\circ} \mathrm{S}-0^{\circ} \mathrm{S}\right.$, $90^{\circ} \mathrm{E}-110^{\circ} \mathrm{E}$ ) parts of the tropical Indian Ocean. Positive DMI is associated with broad-scale increasing (decreasing) surface temperature and precipitation over the western (eastern) part of the tropical Indian Ocean. Positive DMI peaking in autumn is linked with decreasing precipitation over most of MSEA in the following summer (Zhang et al. 2019). On the other hand, Gao et al. (2019) found that extreme droughts over spring are strongly reduced throughout Vietnam and the northwestern part of the peninsula during negative IOD events, and this pattern is further accentuated when these events are also concomitant with La Nina events.

There is a clear shift to predominantly positive IOD states (positive DMI) over recent decades. However as for the IOBM, the DMI correlations to MSEA precipitation obtained here (based on CPC data) are quite low $(\mathrm{R}<0.3)$ and not statistically significant over most of the peninsula in accordance with the study of Tsai et al. (2015). We only found statistically significant negative correlations (R -0.3-0.4) between DMI and precipitation over southern parts of MSEA (sub-regions 1,3 , and 5 ) during autumn (not shown). On the other hand, similarly to IOBM the correlation pattern between DMI and evaporation (Fig. 17c) shows small but statistically significant positive correlations (R 0.3-0.4) along the main pathway of moisture transport towards the MSEA. Largely positive DMI over 1979-2018 (Fig. 17d) is associated with abnormally high SSTs over the northwestern Indian Ocean and Arabian Sea. These higher SSTs may in turn have partially driven the observed evaporation increases in the oceanic moisture sources for MSEA precipitation over that period.

Evaporation anomaly timeseries over oceanic moisture sources show a multi-decadal variation signal with a phase transition in the late 1980's (see Fig. 10). This pattern roughly coincides with a shift in natural climate variability modes of the tropical Indian Ocean with both DMI and IOBM transitioning to a predominantly positive phase driving ocean

Page 13/39 
surface warming and subsequently evaporation increases along the main ocean moisture pathway to the MSEA. Therefore, natural multidecadal variability seems to largely drive evaporation trends in the oceanic moisture sources which in turn could result in increasing precipitation trends around and over the MSEA during recent decades.

\subsection{CMIP5 $21^{\text {st }}$ century projections for mean and extreme precipitation over MSEA}

Long-term amplification of the regional hydrological cycle is further investigated, through analysis of CMIP5 coupled climate models in historical and RCP4.5/8.5 $21^{\text {st }}$ century scenario simulations. We investigated the time evolution of the multi-model (ensemble) mean precipitation averaged over MSEA and its 6 sub-regions, along with evaporation averaged over the three main oceanic moisture sources. Sperber et al. (2013) showed that CMIP5 multi-model mean (MMM) climatological summer precipitation over the historical period is quite consistent with the observed climatological precipitation pattern (from GPCP) over Southeast Asia with a pattern correlation of $\sim 0.9$. The above authors also found that the CMIP5 MMM was more skilful than the CMIP3 MMM for all diagnostics regarding the East Asian Monsoon in terms simulating pattern correlations with respect to observations, while also outperforming the individual models for both the time mean and interannual variability of monsoon rainfall.

Figure 18 shows the evolution of the ensemble-mean area-averaged total annual precipitation anomalies over MSEA together with evaporation anomalies in the three major oceanic moisture sources for this region over the historical (19502005) and $21^{\text {st }}$ century (2006-2100) from RCP4.5 and RCP8.5 simulations. Interestingly, in contrast with observations, the CMIP5 historical simulations indicate a decrease in precipitation over MSEA over roughly the second half of the $20^{\text {th }}$ century (Fig. 18a). Decreasing precipitation during that period follows decreasing evaporation in the major oceanic moisture sources as opposed again to the observational/reanalysis estimates. CMIP5 projections for both RCP4.5 and RCP8.5 scenarios clearly show that over the longer timescale, strong positive trends in precipitation and evaporation emerge following the warming-driven water cycle amplification, with these changes being more pronounced in the higher warming RCP8.5 scenario.

The CMIP5 ensemble mean used here shows pronounced wide-spread positive trends in annual mean and extreme precipitation over the MSEA at the end of $21^{\text {st }}$ century. This signal is spatially coherent and quite robust throughout MSEA, amongst the majority of climate models in both the RCP4.5 and RCP8.5 scenarios (e.g. Sillmann et al. 2013b). Area-averaged total annual precipitation over the whole MSEA increases by 9\% and 14\% (with respect to the historical mean) at the end of $21^{\text {st }}$ century, in RCP4.5 and RCP8.5, respectively. The evolution of precipitation over MSEA during the $21^{\text {st }}$ century closely follows that of the evaporation pattern over the tropical ocean which shows large increases in all three major oceanic moisture sources supplying moisture to the MSEA (Fig. 12b, c, d). In the RCP4.5 (RCP8.5) ensemble mean, evaporation changes over the Arabian Sea, Bay of Bengal, and South China Sea amount to 4.3\% (8.1\%), 5\% (7.4\%), and $4.6 \%(8.4 \%)$, respectively, at the end of $21^{\text {st }}$ century.

Together with investigating changes in the mean precipitation regime over MSEA we also assess changes in extreme rainfall indices based on CMIP5 ensemble daily precipitation data. Results clearly demonstrate an intensification of the regional water cycle with increasing frequency and intensity of extreme precipitation events during the wet season over the $21^{\text {st }}$ century, in accordance with regional high-resolution climate model results over Southeastern Asia (Ngo-Duc et al. 2016; Cruz et al. 2017; Tangang et al, 2018; Ge et al. 2019). Table 3 shows trends for various extreme precipitation indices (area-averaged values over MSEA and over the 6 sub-regions considered here) in the CMIP5 ensemble mean for the historical and the $21^{\text {st }}$ century RCP4.5 and RCP8.5 simulations. As for the mean precipitation, the extreme precipitation indices show widespread significant increases throughout the peninsula (Table 3). Changes in precipitation extremes are again more pronounced in the higher warming RCP8.5 scenario. In the RCP4.5 (RCP8.5) ensemble mean the wet season precipitation (PRCPTOT) and precipitation intensity (SDII) averaged over MSEA increased by 10\% (17\%) and $10 \%(22 \%)$, respectively, at the end of the $21^{\text {st }}$ century. Also, the frequency of extreme events (averaged over MSEA) is 
amplifying with warming with the number of days of heavy rainfall $(>10 \mathrm{~mm} /$ day) increasing by $\sim 13 \%$, whilst the number of days of extreme rainfall ( $>20 \mathrm{~mm} /$ day) increases by $\sim 34 \%$ at the end of the $21^{\text {st }}$ century in RCP8.5.

Extreme rainfall events increase at a much higher rate than wet season mean precipitation throughout the peninsula, highlighting the strongly increased flood risk in coastal regions of MSEA under global warming. These results are consistent with a warming-driven intensification of the hydrological cycle at regional level as MSEA, a "wet" tropical region strongly influenced by the Monsoon, becomes "wetter" in a warming climate. Interestingly, the duration of the dry season also significantly increases in the higher warming scenario (i.e. CDD averaged over MSEA increases by 10\% in RCP8.5), indicating an enhancement of the "wet get wetter, dry get drier" seasonal pattern with warming. However, it is also interesting to note that long-term trends in both mean and extreme precipitation obtained here, even for the highemissions RCP8.5 scenario, are lower than the recent historical 40-year trends inferred from observational rain-gauge data (CPC over 1979-2018, see section 3.1).

\section{Declarations}

\section{Funding}

The research was funded by the UK's National Environment Research Council (NERC) grant CompFlood (NE/S003150/1).

\section{Conflict of interests/competing interests}

The authors declare no conflict of interests or competing financial interests

\section{Availability of data and material}

All data and materials used in this manuscript are freely available and comply with field standards.

\section{Code availability}

Not applicable

\section{Acknowledgements}

All authors time on this paper was funded by the UK's National Environment Research Council (NERC) grant CompFlood (NE/S003150/1) and the National Foundation of Science and Technology Development NAFOSTED-RCUK fund), Ministry of Science and Technology of Vietnam co-funding [Vietnam] CompFlood: Compound Flooding in coastal Vietnam (NE/S003150/1).

\section{Conclusion}

In this study, we investigated large-scale coupled atmosphere/ocean processes that drive variable and extreme rainfall in the MSEA both in the past (1950s to present) and future (present to 2100). Rain-gauge data indicate large increases, exceeding $50 \%$ in precipitation over the eastern coast (Vietnam) and northwest part of the MSEA over the last 40 years. A pronounced widespread increasing precipitation trend persists along the Vietnam coast throughout the year. The increase in mean winter precipitation over Vietnam is accompanied by a significant decrease in the dry season duration as expressed in the large reduction of the CDD index. Together with increasing mean and extreme precipitation, changes in the monsoon onset and duration can have strong implications for agriculture in these regions (Wati et al. 2019).

Over the same period strong warming-driven evaporation increases were observed in most parts of the tropical Indian Ocean including over the major oceanic moisture source regions typically feeding precipitation around and over the 
MSEA. Multidecadal shifts in the natural climatic variability modes of the tropical Indian Ocean such as IOBM and IOD seem to largely drive evaporation trends in the oceanic moisture sources during recent decades.

Moisture budget analysis using ERA5 re-analysis data over 1979-2018 showed an acceleration of the water cycle over the ocean with increasing oceanic moisture transport over both winter and summer moisture pathways towards the MSEA. ERA5 reveals pronounced increases in winter precipitation over the MSEA, in accordance with rain-gauge data, associated with strongly increasing transport of moisture originated from the South China Sea and the western tropical Pacific. On the other hand, there is a large discrepancy for summer trends in that ERA5 is not able to reproduce the strong increases in precipitation over large parts of the MSEA evidenced in the rain-gauge data for the period 1979-2018. Increased oceanic moisture transport results in pronounced moisture convergence within the Bay of Bengal, with only a very small portion of this extra moisture converging over the MSEA.

Our results demonstrate that it is still difficult to assess using re-analysis products the extent to which evaporation in the ocean moisture source regions has contributed to increased precipitation over large parts of the MSEA during recent decades. This is mainly due to the large uncertainties in the re-analyses producing long-term changes of moisture transport and convergence over land, that actually control local continental precipitation. Although the present reanalyses are appropriate tools for establishing climatological mean wind and moisture flux patterns, they are still unreliable to assess long-term trends in water cycling over land.

Our analysis confirms results from previous studies showing a large spread amongst re-analyses in estimating long-term precipitation trends whilst also being inconsistent with observational estimates (Schanze et al 2010; Fasullo 2012; Skliris et al. 2014). However, present model reanalyses and hybrid model/observationally-based datasets show better consistency amongst various products concerning ocean evaporation trends compared with rainfall trends (Skliris et al 2014). Therefore, evaporation in the oceanic moisture sources could be used as a proxy for variability and long-term trends in precipitation over MSEA as evidenced in the CMIP5 ensemble for both historical and RCP projections.

The CMIP5 historical ensemble mean shows a decrease in precipitation over the second half of the $20^{\text {th }}$ century that is not consistent with observations, the latter indicating precipitation increases in large parts of MSEA over that period. Our results suggest that tropical ocean natural variability modes in the adjacent Pacific (ENSO) and Indian (IOD and IOB) oceans may have driven a large proportion of precipitation changes observed in MSEA over the recent historical period. Many CMIP5 models do not properly capture the intensity and time-evolution of natural variability signals, thereby misrepresenting their impact on regional hydrological cycles (e.g. Skliris et al. 2020). However, for future model projections and at the longer timescales natural variability impacts are generally smoothed out. Variability thus contributes little to long-term changes in precipitation, which are instead dominated by the anthropogenic signal of an amplifying water cycle under global warming.

CMIP5 projections over the $21^{\text {st }}$ century clearly show an intensification of the water cycle over MSEA, with increasing frequency and intensity of extreme precipitation events over the wet season. However, projected mean and extreme precipitation trends in the CMIP5 ensemble mean are much lower than the recent historical 40-year trends over large parts of MSEA inferred from observational rain-gauge data. At the same time, in contrast with observations over the last 40 years, the dry season is also projected to increase in the higher warming scenario emphasizing the "wet get wetter, dry get drier" paradigm over time i.e. denoting an amplification of the seasonal pattern of precipitation/drought over MSEA. Importantly, the results demonstrate that the number of days of extreme rainfall and other extreme precipitation indices are increasing much more abruptly than total wet season precipitation in MSEA, and especially in flood prone regions such as the coastal areas of Vietnam and Myanmar. This underlines the increased risk of extreme flooding events in the near future, with potentially severe socio-economic impacts for these regions. 


\section{References}

1. Adler RF, Huffman GJ, Chang A, Ferraro R, Xie P, Janowiak J, Rudolf B, Schneider U, Curtis S, Bolvin D, Gruber A, Susskind J, Arkin P (2003). The Version 2 Global Precipitation Climatology Project (GPCP) Monthly Precipitation Analysis (1979-Present). J Hydrometeor 4:1147-1167.

2. Brubaker KL, Entekhabi D, Eagleson PS (1993). Estimation of continental precipitation recycling. J Clim 6: 10771089.

3. Caesar J, Alexander LV, Trewin B, Tsering K, Sorany L, Vuniyayawa V, Keosavang N, Shimana A, Htay MM, Karmacharya J, Jayasinghearachchi DA, Sakkamar J, Soares E, Hung LT, Thuong LT, Hue CT, Dung NTT, Hung PV, Cuong HD, Cuong NM, Sirabaha

4. S (2011). Changes in temperature and precipitation extremes over the Indo-Pacific region from 1971 to 2005. International Journal of Climatology 31: 791-801.

5. Chen Z, Zhou T, Zhang L, Chen X, Zhang W, Jiang J (2020). Global

6. land monsoon precipitation changes in CMIP6 projections. Geophysical

7. Research Letters, 47, e2019GL086902.

8. Chou C, Chiang JCH, Lan C-W, Chung C-H, Liao Y-C, Lee C-J (2013) Increase in the range between wet and dry season precipitation. Nature Geoscience 6(4):263-267

9. Cruz FT, Narisma GT, Dado JB, Singhruck P, Tangang F, Linarka UA, Wati T, Juneng L, Phan-Van T, Ngo-Duc T, Santisirisomboon J, Gunawan D, E. Aldrian E (2017). Sensitivity of temperature to physical parameterization schemes of RegCM4 over the CORDEX-Southeast Asia region, Int J Climatol 37 (15): 5139-5153 DOI: 10.1002/joc.5151

10. Dun 0 (2011). Environmentally Induced Migration in the Context of Social Vulnerability. 49: 200-223. DOI: 10.1111/j.1468-2435.2010.00646.x

11. Durack PJ, Wijffels SE, Matear RJ (2012) Ocean salinities reveal strong global water cycle intensification during 1950 to 2000 . Science 336:455-458. doi:10.1126/science.1212222

12. Hegerl, GC et al. (2015). Challenges in quantifying changes in the global water cycle. Bulletin of the American Meteorological Society, 96(7), 1097-1115. DOI: 10.1175/BAMS-D-13-00212.1

13. Fasullo J (2012). A mechanism for land-ocean contrasts in global monsoon trends in a warming climate. Clim Dyn 39:1137-1147. DOI 10.1007/s00382-011-1270-3

14. Gao Q-G, Sombutmounvong V, Xionag L, Lee J-H, Kim J-S (2019). Analysis of Drought-Sensitive Areas and Evolution Patterns through Statistical Simulations of the Indian Ocean Dipole Mode. Water 11: 1302. doi:10.3390/w11061302

15. Ge F, Zhu S, Peng T, Zhao Y, Sielmann F, Fraedrich K, Zhi X, Liu X, Tang W, Ji L (2019). Risks of precipitation extremes over Southeast Asia: does $1.5^{\circ} \mathrm{C}$ or $2^{\circ} \mathrm{C}$ global warming make a difference? Environ. Res. Lett. 14: 044015

16. Good SA, Martin MJ, Rayner NA (2013) Quality controlled ocean temperature and salinity profiles and monthly objective analyses with uncertainty estimates. J Geophys Res Oceans 118:6704-6716

17. Held IM, Soden BJ (2006) Robust responses of the hydrological cycle to global warming. J Clim 19:5686-5699. doi:10.1175/JCLI3990.1.

18. Hersbach H, et al. (2020). The global ERA5 reanalysis. Q J R Meteorol Soc. 146:1999-2049. doi: 10.1002/qj.3803

19. Huang Y, Wu B, Li T, Liu B, Zhou T (2019). Interdecadal Indian Ocean Basin Mode Driven by Interdecadal Pacific Oscillation: A Season-Dependent Growth Mechanism. J Clim 32 (7): 2057-2073. doi: 10.1175/JCLI-D-18-0452.1

20. Klein SA, Soden BJ, Lau N-C (1999) Remote sea surface variations during ENSO: evidence for a tropical atmospheric bridge. J Clim 12:917-932. 
21. Liu C, Allan RP (2012) Multi-satellite observed responses of precipitation and its extremes to interannual climate variability. J Geophys Res 117:D03101. doi:10.1029/2011JD016568

22. Liu C, Allan RP, Huffman GJ (2012) Co-variation of temperature and precipitation in CMIP5 models and satellite observations. Geophys Res Lett 39:L13803. doi:10.1029/2012GL052093

23. Ngo-Duc T, Tangang FT, Santisirisomboon J, Cruz F, Trinh-Tuan L, Nguyen-Xuan T, Phan-Van T, Juneng L, Narisma G, Singhruck P, Gunawan D, Aldrian E (2016) Performance evaluation of RegCM4 in simulating extreme rainfall and temperature indices over the CORDEX-Southeast Asia region, Int J Climatol 37: 1634-1647, doi: 10.1002/joc.4803

24. Nguyen et al. 2014. Variations of surface temperature and rainfall in Vietnam from 1971 to 2010. Int. J. Climatol. 34: 249-264.

25. Nicholls RJ, Wong PP, Burkett VR, Codignotto JO, Hay, JE, McLean RF, Ragoonaden S, Woodroffe CD (2007) Coastal systems and low-lying areas. In: Climate Change 2007: Impacts, Adaptation and Vulnerability. Contribution of Working Group II to the Fourth Assessment Report of the Intergovernmental Panel on Climate Change, [Parry ML, Canziani OF, Palutikof JP, van der Linden PJ, and Hanson CE (eds.)]. Cambridge University Press, Cambridge, UK and New York, NY, USA, pp. 315-356.

26. O'Gorman PA (2015) Precipitation extremes under climate change. Curr Clim Change Rep 1:49-59. DOI 10.1007/s40641-015-0009-3

27. Pan S, Pan N, Tian H, Friedlingstein P, Sitch S, Shi H, Arora VK, Haverd V, Jain AK, Kato E, Lienert S, Lombardozzi D, Nabel JEMS, Ottlé C, Poulter B, Zaehle S, Running, SW (2020). Evaluation of global terrestrial evapotranspiration using state-of-the-art approaches in remote sensing, machine learning and land surface modeling, Hydrol Earth Syst Sci, 24:1485-1509. https://doi.org/10.5194/hess-24-1485-2020.

28. Roxy MK, Ritika K, Terray P, Masson S (2014). The Curious Case of Indian Ocean Warming. J Clim 27:8501-8509.

29. Saji NH, Goswami BN, Vinayachandran PN, Yamagata T (1999) A dipole

30. mode in the tropical Indian Ocean. Nature 401(6):360-363

31. Schurer AP, Ballinger AP, Friedman AR, Hegerl GC (2020) Human influence strengthens the contrast between tropical wet and dry regions. Environ Res Lett 15: 104026.

32. Sillmann J, Kharin VV, Zhang X, Zwiers FW, Bronaugh D (2013a) Climate extremes indices in the CMIP5 multimodel ensemble: Part 1. Model evaluation in the present climate. J Geophys Res Atmos 118: 1716-1733.

Doi:10.1002/jgrd.50203

33. Sillmann J, Kharin VV, Zhang X, Zwiers FW, Bronaugh D (2013b) Climate extremes indices in the CMIP5 multimodel ensemble: Part 2. Future climate projections, J Geophys Res Atmos 118: 2473-2493. Doi:10.1002/jgrd.50188

34. Skliris N., Marsh R, Josey SA, Good SA, Liu C, Allan RP (2014). Salinity changes in the World Ocean since 1950 in relation to changing surface freshwater fluxes. Clim Dyn 43: 709-736.

35. Skliris N, Zika JD, Nurser G, Josey SA, Marsh R (2016). Global water cycle amplifying at less than the ClausiusClapeyron rate. Scientific Reports 6, 38752. doi: 10.1038/srep38752.

36. Skliris N, Marsh R, Mecking J, Zika JD (2020). Changing water cycle and freshwater transports in the Atlantic Ocean in observations and CMIP5 models. Clim Dyn. DOI: 10.1007/s00382-020-05261-y

37. Sperber KR, Annamalai H, Kang I-S, Kitoh A, Moise A, Turner A, Wang B, Zhou T (2013). The Asian summer monsoon: an intercomparison of CMIP5 vs. CMIP3 simulations of the late 20th century. Clim Dyn 41:2711-2744. DOI $10.1007 / \mathrm{s} 00382-012-1607-6$

38. Sun, B., Li, H., \& Zhou, B. (2019). Interdecadal variation of Indian Ocean basin mode and the impact on Asian summer climate. Geophysical Research Letters, 46: 12,388-12,39. DOI: 10.1029/2019GL085019

39. Sun B, Wang H (2015). Analysis of the major atmospheric moisture sources affecting

40. three sub-regions of East China. Int. J. Climatol. 35: 2243-2257.

Page 18/39 
41. Tangang $F$ et al (2018). Future changes in annual precipitation extremes over Southeast Asia under global warming of $2^{\circ} \mathrm{C}$, APN Science Bulletin 8 (1), doi: 10.30852/sb.2018.436

42. Taylor KE, Stouffer RJ, Meehl GA (2012). An overview of CMIP5 and the experiment design. Bull. Amer. Meteor. Soc. 93:485-498.

43. Tsai C, Behera SK, Waseda T (2015). MSEA Monsoon indices. Scientific Reports 5: 8107, DOI: 10.1038/srep08107.

44. van der Ent RJ, Savenije HHG (2013). Oceanic sources of continental precipitation and the correlation with sea surface temperature. Water Resour. Res 49:3993-4004. doi:10.1002/wrcr.20296

45. Wang Z, Duan, A. Yang S, Ullah K (2017), Atmospheric moisture budget and its regulation on the variability of summer precipitation over the Tibetan

46. Plateau, J. Geophys. Res. Atmos., 122, 614-630, doi:10.1002/2016JD025515.

47. Wang Z, Chang, C-P (2012). A numerical study of the interaction between the largescale monsoon circulation and orographic precipitation over South and Southeast Asia. J. Clim. 25: 2440-2455.

48. Wati T, Kusumaningtyas SDA, Aldrian E (2019). Study of season onset based on water requirement assessment, IOP Conference Series: Earth and Environmental Science 299 012042, doi: 10.1088/1755-1315/299/1/012042.

49. Wu G, Liu Y, He B, Bao Q, Duan A Jin, F-F (2012). Thermal controls on the Asian summer monsoon Sci. Rep. 2: 404

50. Yang J, Liu Q, Liu Z, Wu L, Huang F (2009). Basin mode of Indian Ocean sea surface temperature and Northern Hemisphere circumglobal teleconnection. Geophys Res Lett 36:L19705, doi:10.1029/2009GL039559.

51. Yanai M, Wu G-X (2006). Effects of the Tibetan Plateau. Chapter 13, The Asian Monsoon (eds Wang, B. et al.). Springer, Chichester.

52. Yatagai A et al 2012 APHRODITE: constructing a long-term daily gridded precipitation dataset for Asia based on a dense network of rain gauges Bull. Am. Meteorol. Soc. 93 1401-15.

53. Yu L, Jin X, Weller RA (2008) Multidecade global flux datasets from the Objectively Analyzed Air-sea Fluxes (OAFlux) Project: Latent and Sensible Heat Fluxes, Ocean Evaporation and Related Surface Meteorological Variables. OAFlux Project Technical Report (OA2008-01), Woods Hole Oceanographic Institution.

54. Zhang Y, Peña-Arancibia JL, McVicar TR, Chiew FHS, Vaze J, Liu C, Lu X, Zheng H, Wang Y, Liu YY, Miralles DG, Pan M (2016). Multi-decadal trends in global terrestrial evapotranspiration and its components. Scientific Reports 6:19124.

55. Zhou, S., Huang, P., Huang, G., \& Hu, K. (2019). Leading source and constraint on the systematic spread of the changes in East Asian and western North Pacific summer monsoon. Environmental Research Letters, 14, 124059. https://doi.org/10.1088/1748-9326/ab547c

56. Zika JD, Skliris N, Blaker AT, Marsh R, Nurser AJG, Josey SA (2018) Improved estimates of water cycle change from ocean salinity: the key role of ocean warming. Environ Res Lett 13(7):1-10. DOI: 10.1088/1748-9326/aace4 2

\section{Tables}

Table 1. Precipitation annual and seasonal trends (mm/day/40yrs) over 1979-2018 averaged over MSEA and the 6 subregions considered in this study based on the Global Unified Gauge-Based Analysis of Daily Precipitation - Climate Prediction centre (CPC). Symbol ' $*$ ' denotes trends that are not statistically significant at the $95 \%$ confidence interval. Values in parentheses indicate percentage of change (w.r.t the climatological mean) over 1979-2018. 


\begin{tabular}{|llllll|}
\hline Region/Period & Annual & Winter (DJF) & Spring (MAM) & Summer (JJA) & Autumn (SON) \\
\hline MSEA & $1.00(24 \%)$ & $0.98(73 \%)$ & $0.74(25 \%)$ & $0.97(14 \%)^{\star}$ & $0.78(15 \%)$ \\
\hline 1. S. Vietnam & $1.87(60 \%)$ & $1.45(135 \%)$ & $1.11(76 \%)$ & $2.79(78 \%)$ & $2.04(35 \%)$ \\
\hline 2. N. Vietnam & $2.22(55 \%)$ & $2.03(130 \%)$ & $0.82(37 \%)$ & $2.73(52 \%)$ & $3.37(49 \%)$ \\
\hline 3. C. MSEA & $-0.04(1 \%)^{*}$ & $0.21(56 \%)$ & $0.23(7 \%)$ & $-0.60(9 \%)^{\star}$ & $-0.04(1 \%)^{*}$ \\
\hline 4. N. MSEA & $-0.07(3 \%)^{*}$ & $0.09(21 \%)^{*}$ & $0.17(8 \%)^{*}$ & $-0.14(2 \%)^{*}$ & $-0.34(12 \%)^{\star}$ \\
\hline 5. S. Myanmar & $0.42(8 \%)^{\star}$ & $1.37(131 \%)$ & $0.82(21 \%)^{*}$ & $-0.87(9 \%)^{*}$ & $0.40(6 \%)^{*}$ \\
\hline 6. N. Myanmar & $1.69(53 \%)$ & $0.02(5.5 \%)^{*}$ & $1.80(73 \%)$ & $3.49(48 \%)$ & $1.18(45 \%)$ \\
\hline
\end{tabular}

Table 2. Trends in Extreme Precipitation Indices averaged over MSEA and the 6 sub-regions considered in this study based on the Global Unified Gauge-Based Analysis of Daily Precipitation - Climate Prediction Centre (CPC) over 19782018. Symbol ' $*$ ' denotes trends that are not statistically significant at the $95 \%$ confidence interval. Values in parentheses indicate percentage of change (w.r.t the climatological mean) over 1979-2018.

\begin{tabular}{|c|c|c|c|c|c|}
\hline Region & $\begin{array}{l}\text { PRCPTOT } \\
\text { (mm/40yrs) }\end{array}$ & $\begin{array}{l}\text { SDII } \\
\text { (mm/day/40yrs) }\end{array}$ & $\begin{array}{l}\text { CDD } \\
\text { (days/40yrs) }\end{array}$ & $\begin{array}{l}\mathrm{R} 10 \mathrm{~mm} \\
\text { (days/40yrs) }\end{array}$ & $\begin{array}{l}\text { R20mm } \\
\text { (days/40yrs) }\end{array}$ \\
\hline MSEA & 162 (19\%) & $0.26(3 \%)^{*}$ & $-3.5(11 \%)^{*}$ & $4.5(18 \%)$ & $2.3(22 \%)$ \\
\hline $\begin{array}{l}\text { 1.S. } \\
\text { Vietnam }\end{array}$ & $381(57 \%)$ & $-0.42(4 \%)^{\star}$ & $-27.6(69 \%)$ & $12.6(67 \%)$ & $5.4(62 \%)$ \\
\hline $\begin{array}{l}\text { 2. N. } \\
\text { Vietnam }\end{array}$ & $466(46 \%)$ & $2.00(17 \%)$ & $-15.2(59 \%)$ & $12.9(45 \%)$ & $7.2(54 \%)$ \\
\hline 3. C. MSEA & $164(19 \%)$ & $-0.69(7 \%)^{\star}$ & $-7.9(39 \%)$ & $5.1(20 \%)$ & $1.8(15 \%)^{\star}$ \\
\hline 4. N. MSEA & $-13(1 \%)^{*}$ & $0.09(1 \%)^{*}$ & $3.0(6 \%)^{\star}$ & $-0.3(1 \%)^{\star}$ & $-0.1(1 \%)^{*}$ \\
\hline $\begin{array}{l}\text { 5. S. } \\
\text { Myanmar }\end{array}$ & $60(9 \%)^{*}$ & $-3.2(29 \%)$ & $-6.1(26 \%)$ & $2.5(12 \%)^{\star}$ & $0.5(5 \%)^{*}$ \\
\hline $\begin{array}{l}\text { 6. N. } \\
\text { Myanmar }\end{array}$ & $538(54 \%)$ & $3.44(35 \%)$ & $-0.4(1 \%)$ & $13.7(47 \%)$ & $7.6(56 \%)$ \\
\hline
\end{tabular}

Table 3. Trends in Extreme Precipitation Indices (PRCPTOT, SDII, CDD, R10mm, R20mm) averaged over MSEA and the 6 sub-regions considered in this study based on the CMIP5 ensemble mean in the RCP4.5 and RCP8.5 scenario simulations. Values in parentheses indicate percentage of change (w.r.t the historical mean). Symbol ' $*$ ' denotes trends that are not statistically significant at the $95 \%$ confidence interval. 


\begin{tabular}{|c|c|c|c|c|c|c|c|c|c|c|}
\hline \multirow[t]{2}{*}{ Region } & \multicolumn{2}{|c|}{$\begin{array}{l}\text { РRCРTOT } \\
\text { mm/cent. }\end{array}$} & \multicolumn{2}{|c|}{$\begin{array}{l}\text { SDII } \\
\text { mm/day/cent. }\end{array}$} & \multicolumn{2}{|c|}{$\begin{array}{l}\text { CDD } \\
\text { days/cent. }\end{array}$} & \multicolumn{2}{|c|}{$\begin{array}{l}\text { R10mm } \\
\text { days/cent. }\end{array}$} & \multicolumn{2}{|c|}{$\begin{array}{l}\text { R20mm } \\
\text { days/cent. }\end{array}$} \\
\hline & RCP4.5 & RCP8.5 & RCP4.5 & RCP8.5 & RCP4.5 & RCP8.5 & RCP4.5 & RCP8.5 & RCP4.5 & RCP8.5 \\
\hline MSEA & $\begin{array}{l}162 \\
(10 \%)\end{array}$ & $\begin{array}{l}241 \\
(17 \%)\end{array}$ & $\begin{array}{l}0.90 \\
(10 \%)\end{array}$ & $\begin{array}{l}1.98 \\
(22 \%)\end{array}$ & $\begin{array}{l}-1.1 \\
(2 \%)^{\star}\end{array}$ & $\begin{array}{l}4.1 \\
(8 \%)\end{array}$ & $\begin{array}{l}4.7 \\
(10 \%)\end{array}$ & $\begin{array}{l}6.2 \\
(13 \%)\end{array}$ & $\begin{array}{l}3.0 \\
(20 \%)\end{array}$ & $\begin{array}{l}5.1 \\
(34 \%)\end{array}$ \\
\hline $\begin{array}{l}\text { 1. South } \\
\text { Vietnam }\end{array}$ & $\begin{array}{l}106 \\
(6 \%)\end{array}$ & $\begin{array}{l}223 \\
(13 \%)\end{array}$ & $\begin{array}{l}0.53 \\
(6 \%)\end{array}$ & $\begin{array}{l}1.38 \\
(16 \%)\end{array}$ & $\begin{array}{l}1.5 \\
(4 \%)^{\star}\end{array}$ & $\begin{array}{l}4.5 \\
(11 \%)\end{array}$ & $\begin{array}{l}3.7 \\
(6 \%)\end{array}$ & $\begin{array}{l}7.7 \\
(13 \%)\end{array}$ & $\begin{array}{l}2.1 \\
(13 \%)\end{array}$ & $\begin{array}{l}5.0 \\
(31 \%)\end{array}$ \\
\hline $\begin{array}{l}\text { 2. North } \\
\text { Vietnam }\end{array}$ & $\begin{array}{l}115 \\
(9 \%)\end{array}$ & $\begin{array}{l}161 \\
(12 \%)\end{array}$ & $\begin{array}{l}0.75 \\
(9 \%)\end{array}$ & $\begin{array}{l}1.63 \\
(19 \%)\end{array}$ & $\begin{array}{l}-1.2 \\
(3 \%)^{*}\end{array}$ & $\begin{array}{l}4.3 \\
(10 \%)\end{array}$ & $\begin{array}{l}3.6 \\
(9 \%)\end{array}$ & $\begin{array}{l}5.1 \\
(12 \%)\end{array}$ & $\begin{array}{l}2.3 \\
(19 \%)\end{array}$ & $\begin{array}{l}3.9 \\
(33 \%)\end{array}$ \\
\hline $\begin{array}{l}\text { 3. Central } \\
\text { MSEA }\end{array}$ & $\begin{array}{l}131 \\
(9 \%)\end{array}$ & $\begin{array}{l}212 \\
(12 \%)\end{array}$ & $\begin{array}{l}0.74 \\
(8 \%)\end{array}$ & $\begin{array}{l}1.66 \\
(18 \%)\end{array}$ & $\begin{array}{l}-1.2 \\
(2 \%)^{\star}\end{array}$ & $\begin{array}{l}2.6 \\
(5 \%)\end{array}$ & $\begin{array}{l}4.2 \\
(8 \%)\end{array}$ & $\begin{array}{l}6.7 \\
(13 \%)\end{array}$ & $\begin{array}{l}2.8 \\
(22 \%)\end{array}$ & $\begin{array}{l}5.1 \\
(41 \%)\end{array}$ \\
\hline $\begin{array}{l}\text { 4. North } \\
\text { MSEA }\end{array}$ & $\begin{array}{l}182 \\
(13 \%)\end{array}$ & $\begin{array}{l}266 \\
(19 \%)\end{array}$ & $\begin{array}{l}1.01 \\
(11 \%)\end{array}$ & $\begin{array}{l}2.24 \\
(24 \%)\end{array}$ & $\begin{array}{l}-1.61 \\
(3 \%)\end{array}$ & $\begin{array}{l}3.45 \\
(6 \%)\end{array}$ & $\begin{array}{l}4.9 \\
(10 \%)\end{array}$ & $\begin{array}{l}6.4 \\
(13 \%)\end{array}$ & $\begin{array}{l}3.3 \\
(23 \%)\end{array}$ & $\begin{array}{l}5.5 \\
(38 \%)\end{array}$ \\
\hline $\begin{array}{l}\text { 5. South } \\
\text { Myanmar }\end{array}$ & $\begin{array}{l}230 \\
(14 \%)\end{array}$ & $\begin{array}{l}277 \\
(17 \%)\end{array}$ & $\begin{array}{l}1.3 \\
(12 \%)\end{array}$ & $\begin{array}{l}2.3 \\
(21 \%)\end{array}$ & $\begin{array}{l}-2.6 \\
(3 \%)^{\star}\end{array}$ & $\begin{array}{l}2.7 \\
(3 \%)^{\star}\end{array}$ & $\begin{array}{l}6.3 \\
(11 \%)\end{array}$ & $\begin{array}{l}6.4 \\
(12 \%)\end{array}$ & $\begin{array}{l}4.2 \\
(23 \%)\end{array}$ & $\begin{array}{l}5.0 \\
(29 \%)\end{array}$ \\
\hline $\begin{array}{l}\text { 6. North } \\
\text { Myanmar }\end{array}$ & $\begin{array}{l}204 \\
(12 \%)\end{array}$ & $\begin{array}{l}354 \\
(21 \%)\end{array}$ & $\begin{array}{l}1.1 \\
(10 \%)\end{array}$ & $\begin{array}{l}2.5 \\
(24 \%)\end{array}$ & $\begin{array}{l}0.3 \\
(0 \%)^{\star}\end{array}$ & $\begin{array}{l}4.9 \\
(9 \%)\end{array}$ & $\begin{array}{l}4.6 \\
(9 \%)\end{array}$ & $\begin{array}{l}6.6 \\
(13 \%)\end{array}$ & $\begin{array}{l}3.1 \\
(16 \%)\end{array}$ & $\begin{array}{l}5.8 \\
(30 \%)\end{array}$ \\
\hline
\end{tabular}

Figures 

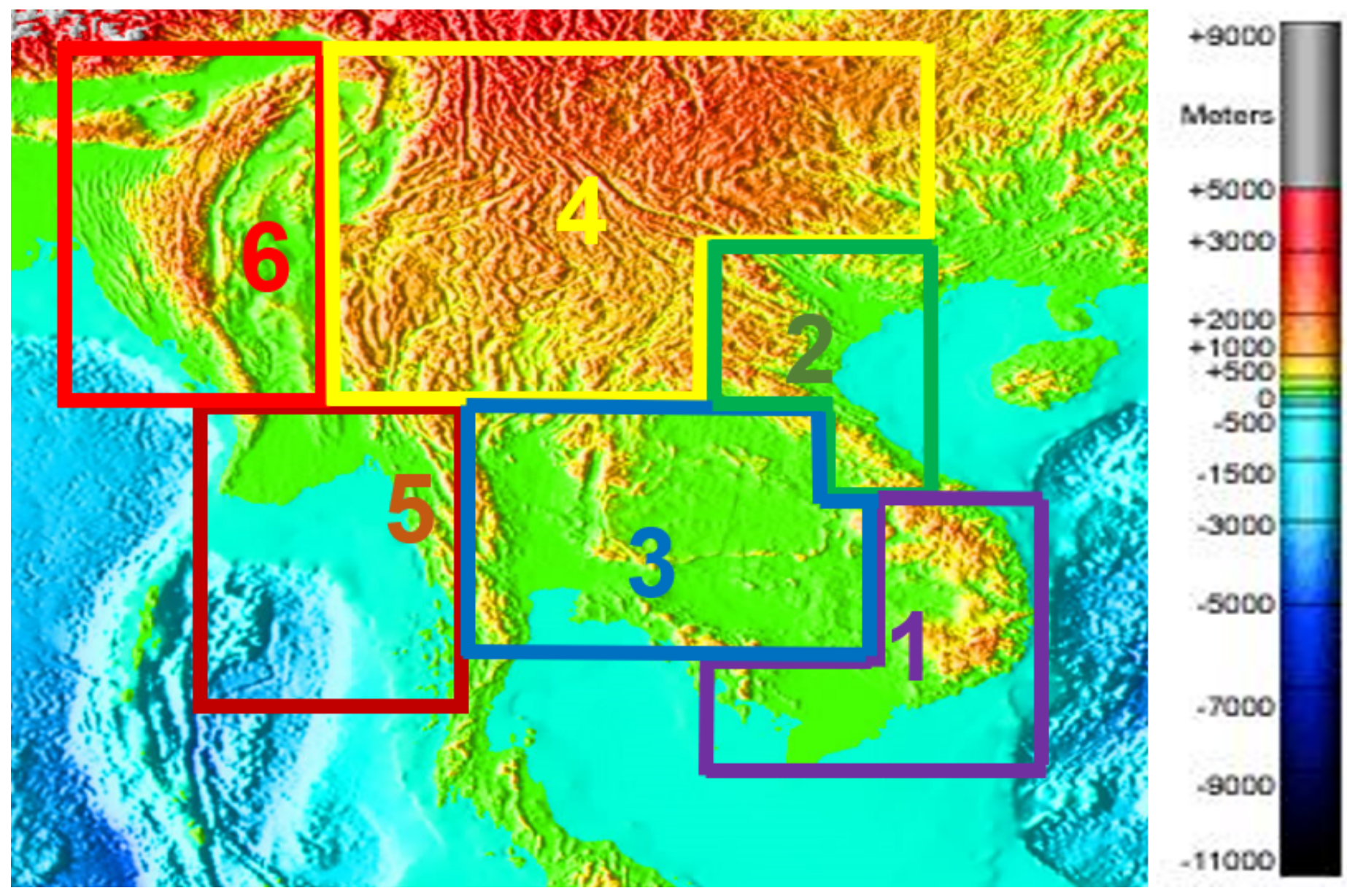

Figure 1

Mainland Southeast Asia topographical map (National Oceanic and Atmospheric Administration, http://www.ngdc.noaa.gov/mgg/image/2minrelief.html) based on ETOPO2v2 topography/bathymetry 2-minute dataset. The 6 sub-regions for which area-averaged mean and extreme precipitation changes are investigated here are also depicted: (1) South Vietnam, (2) North Vietnam, (3) Central MSEA, (4) North MSEA, (5) South Myanmar, (6) North Myanmar 
(a)

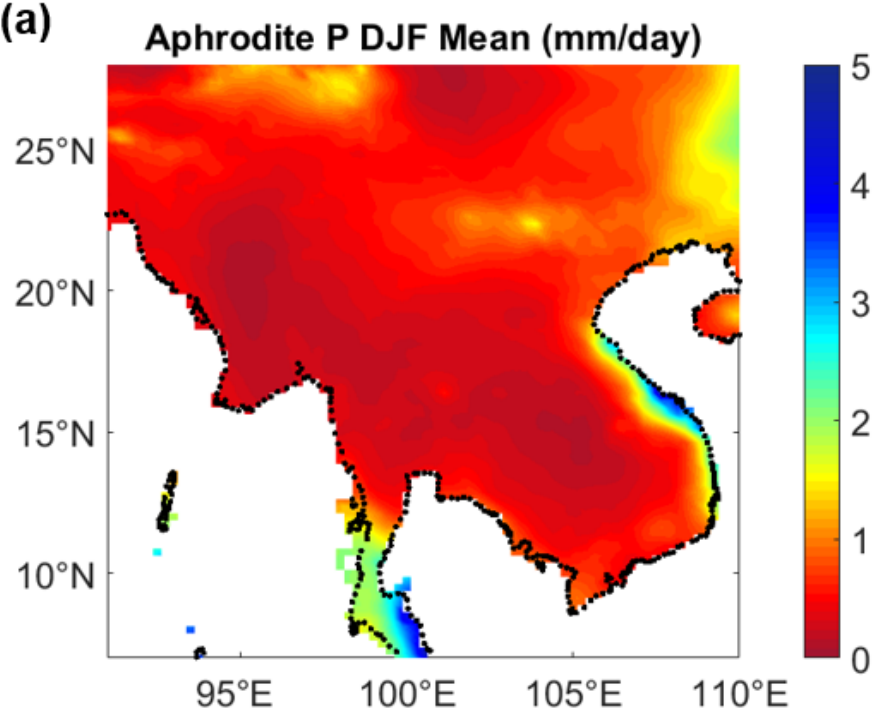

(c) Aphrodite P JJA Mean (mm/day)

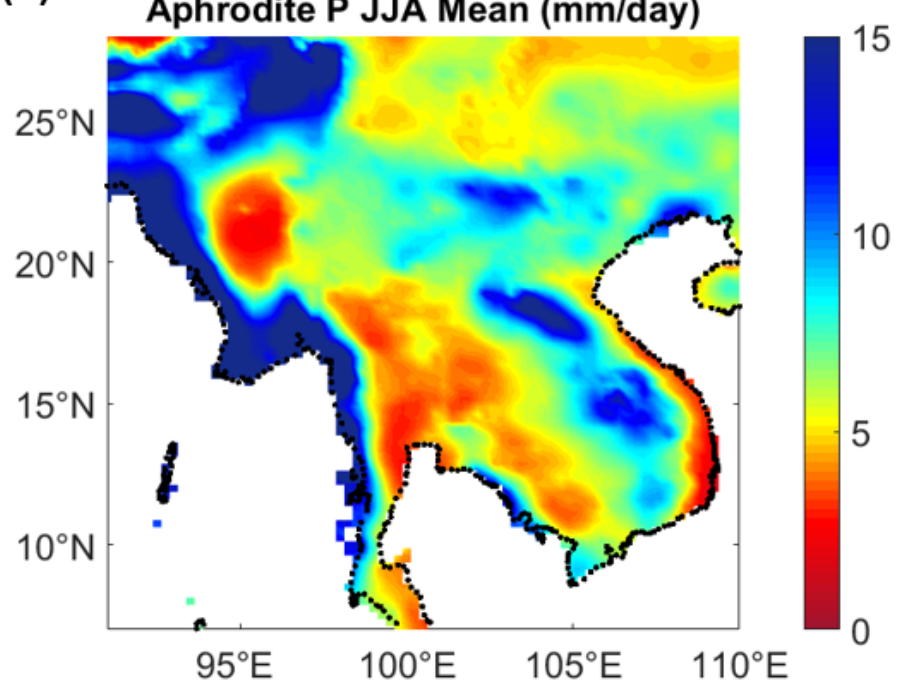

(b)

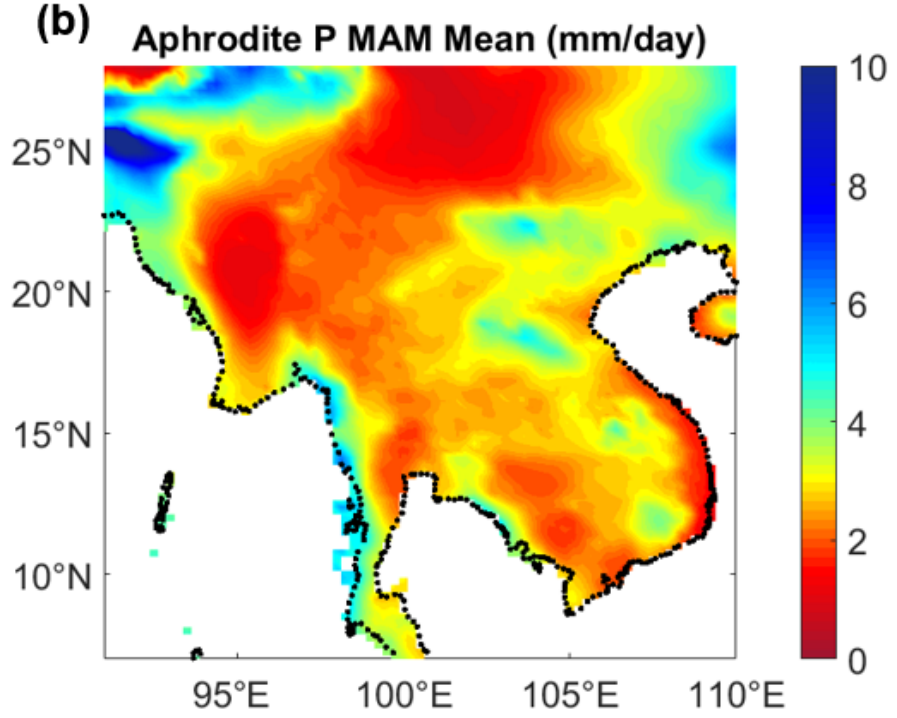

(d)

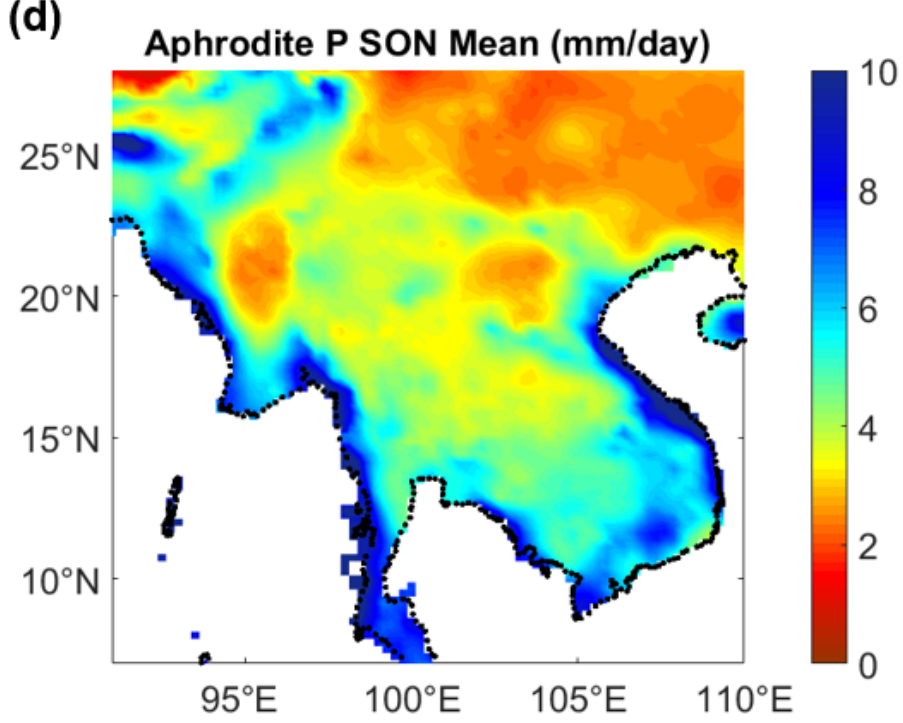

Figure 2

Climatological mean seasonal precipitation patterns over MSEA based on the rain-gauge-based APHRODITE dataset: (a) Winter (Dec-Feb); (b) Spring (Mar-May); (c) Summer (Jun-Aug); (d) Autumn (Sep-Nov). 
(a)

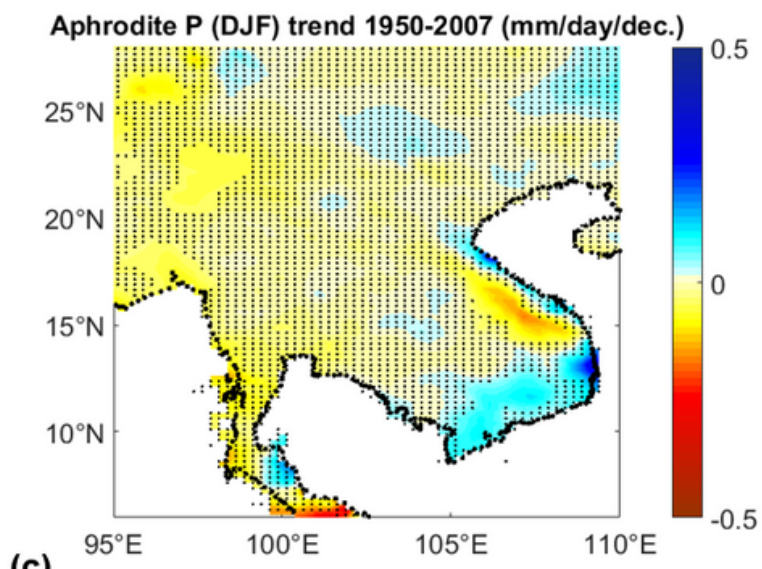

(c)

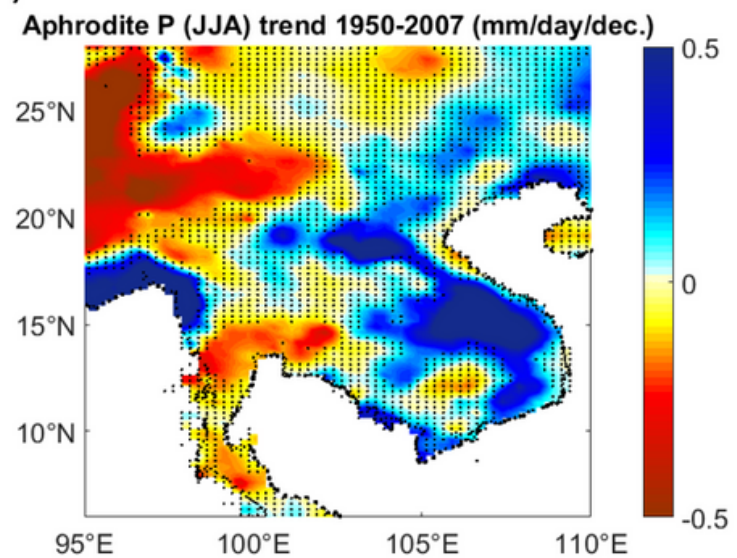

(b)

Aphrodite P (MAM) trend 1950-2007 (mm/day/dec.)

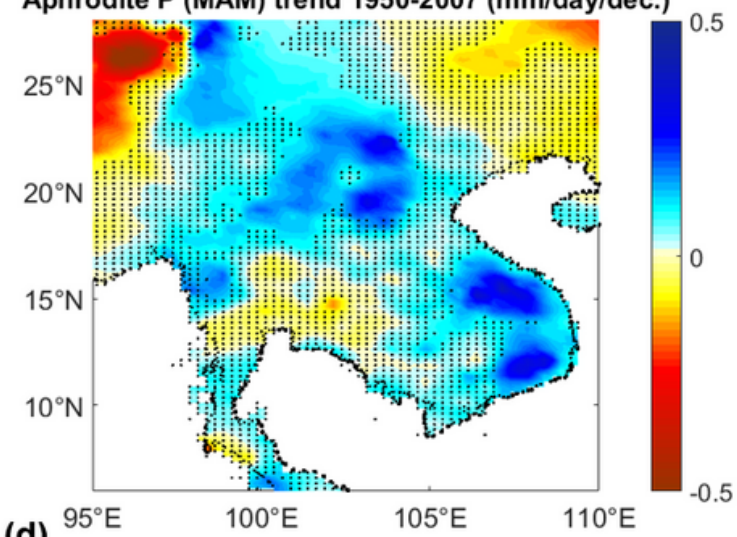

Aphrodite P (SON) trend 1950-2007 (mm/day/dec.)

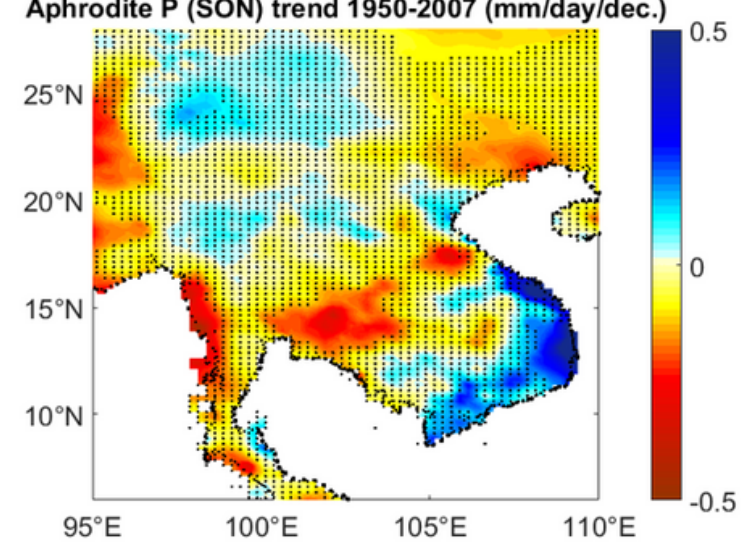

Figure 3

Seasonal precipitation trends (mm/day/decade over 1950-2007 based on the rain-gauge-based APHRODITE dataset: (a) Winter (Dec-Feb); (b) Spring (Mar-May); (c) Summer (Jun-Aug); (d) Autumn (Sep-Nov). Regions where the linear trend is not significant at the $95 \%$ confidence interval are stippled. 
(a)

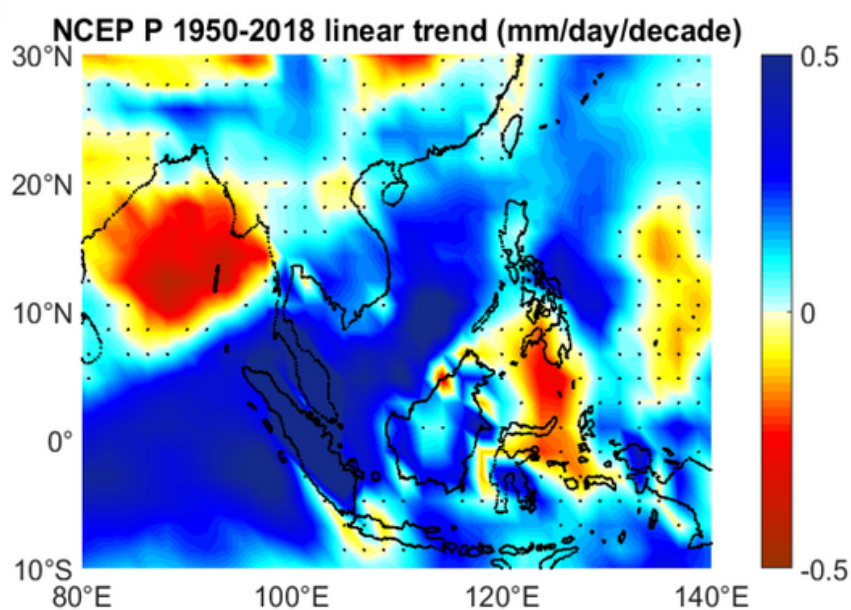

(b)

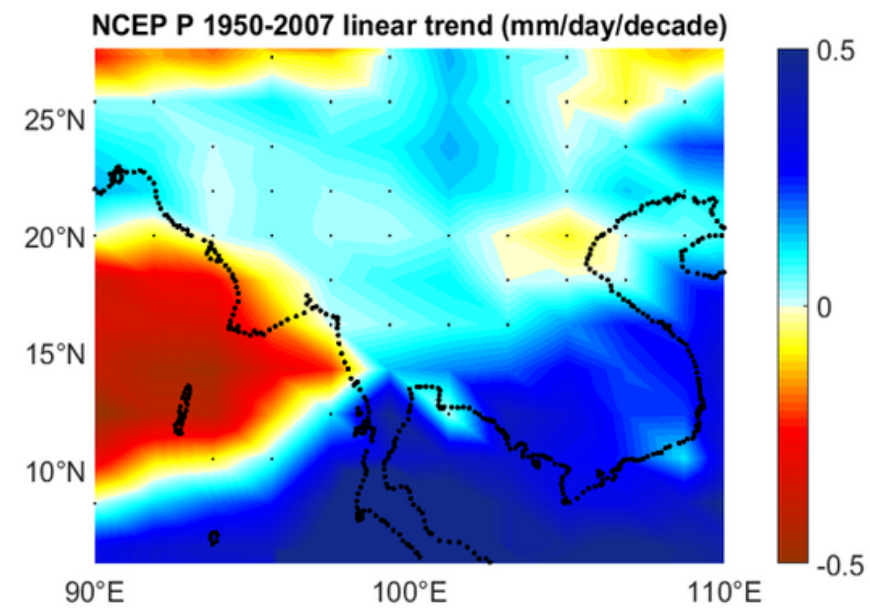

(c)

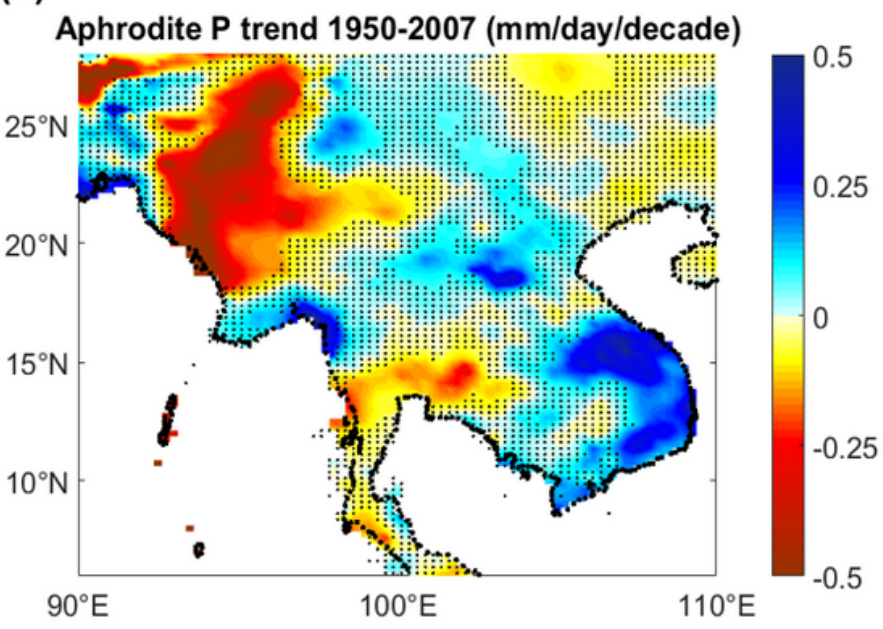

Figure 4

Annual precipitation linear trends (mm/day/decade): (a) NCEP/NCAR over 1950-2018; (b) NCEP/NCAR over 1950-2007; (c) APHRODITE over 1950-2007. Regions where the linear trend is not significant at the $95 \%$ confidence interval are stippled. 
(a)

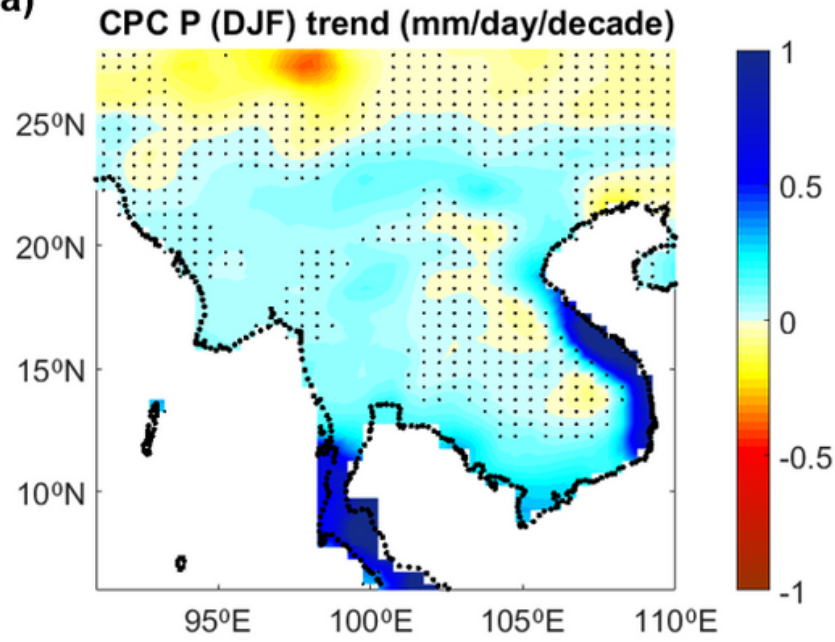

(c)

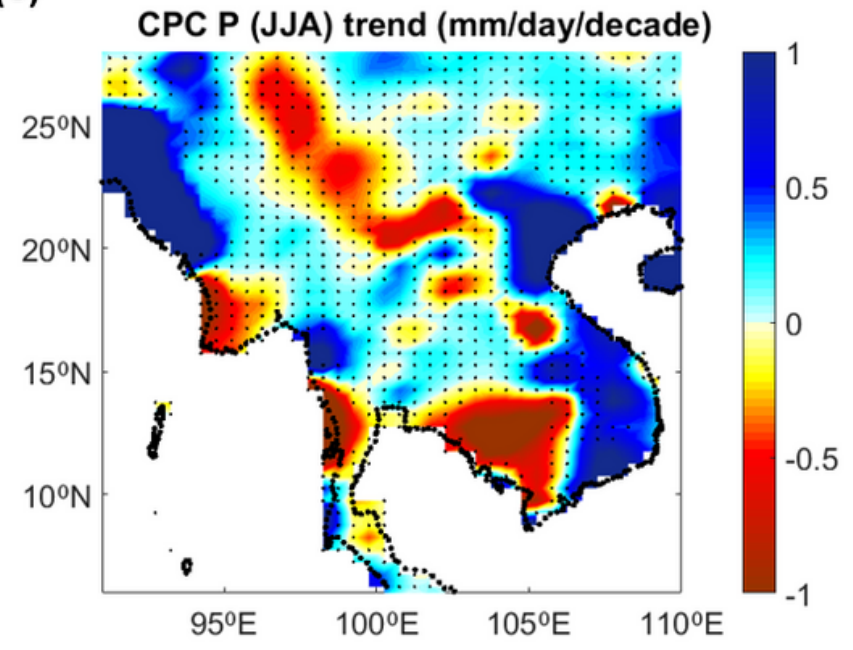

(b)

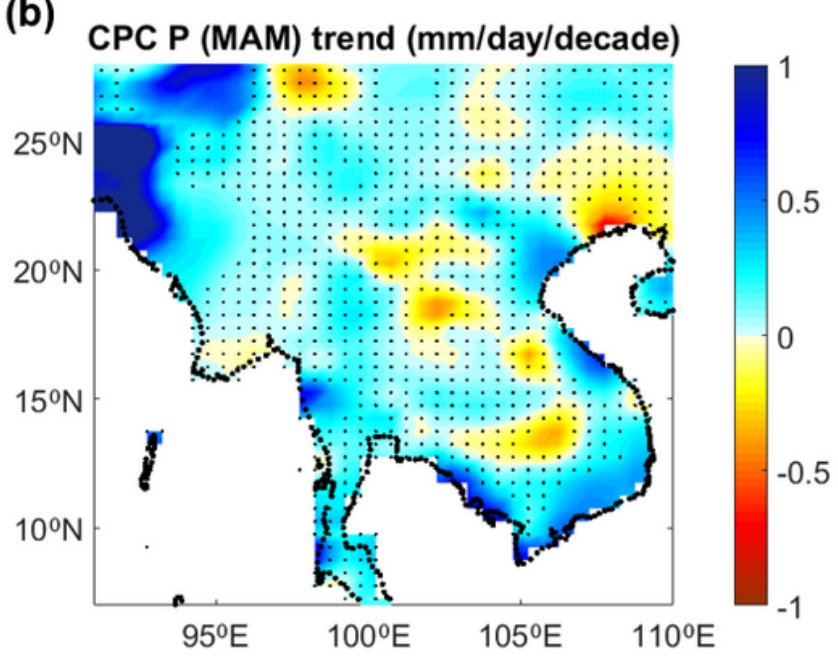

(d)

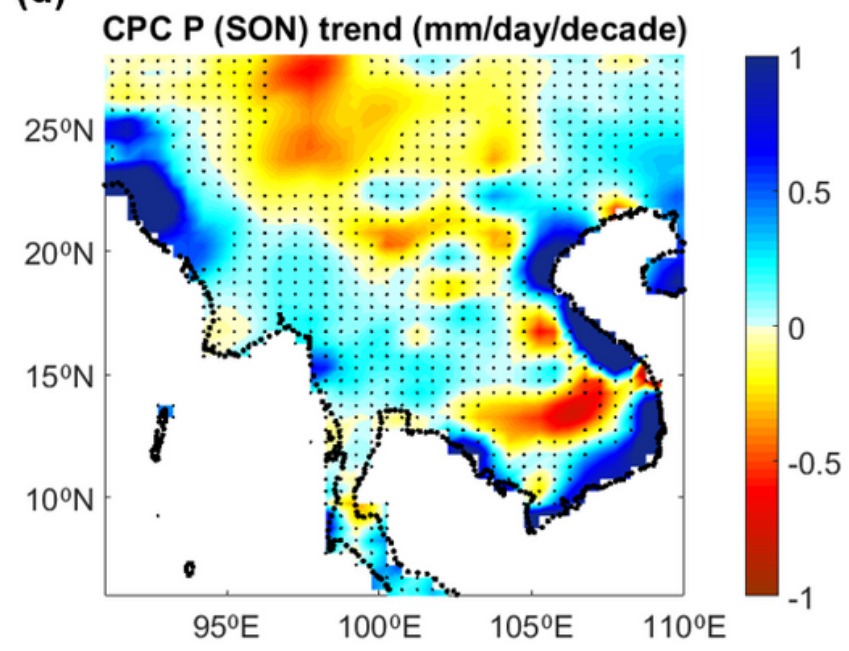

Figure 5

Seasonal precipitation trends (mm/day/decade) over 1979-2018 from the Global Unified Gauge-Based Analysis of Daily Precipitation - Climate Prediction Centre (CPC) dataset: (a) Winter (Dec-Feb); (b) Spring (Mar-May); (c) Summer (JunAug); (d) Autumn (Sep-Nov). Regions where the linear trend is not significant at the $95 \%$ confidence interval are stippled. 

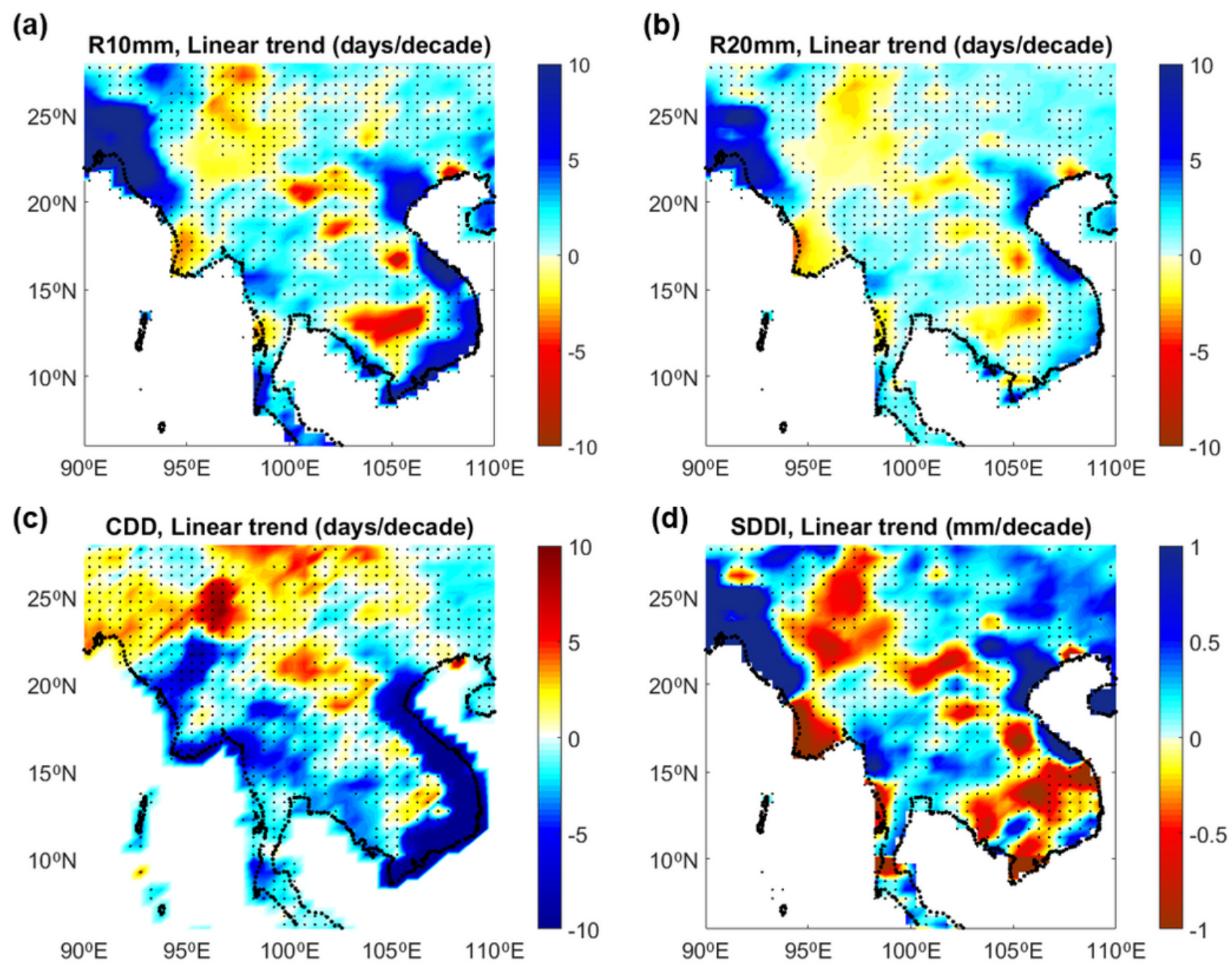

Figure 6

Trends over 1979-2018 in extreme precipitation indices from the Global Unified Gauge-Based Analysis of Daily Precipitation - Climate Prediction Centre (CPC) dataset. (a) R10mm: Number of days of heavy precipitation (P>10mm), (b) R20mm: Number of days of very heavy precipitation ( $P>20 \mathrm{~mm}),(c)$ CDD: Number of Consecutive Dry Days, (d) SDII: Simple daily precipitation intensity. Regions where the linear trend is not significant at the $95 \%$ confidence interval are stippled. 
(a)

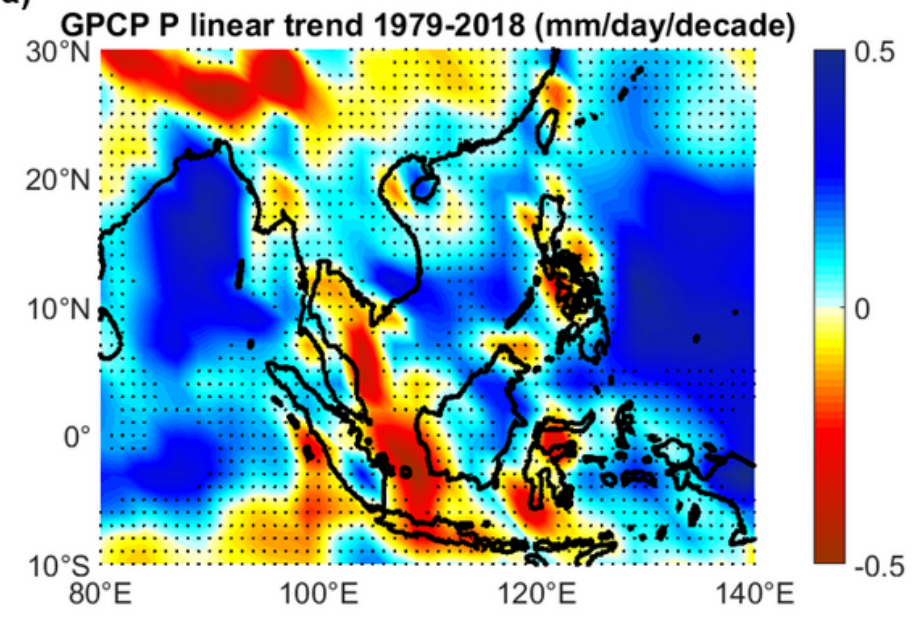

(b)

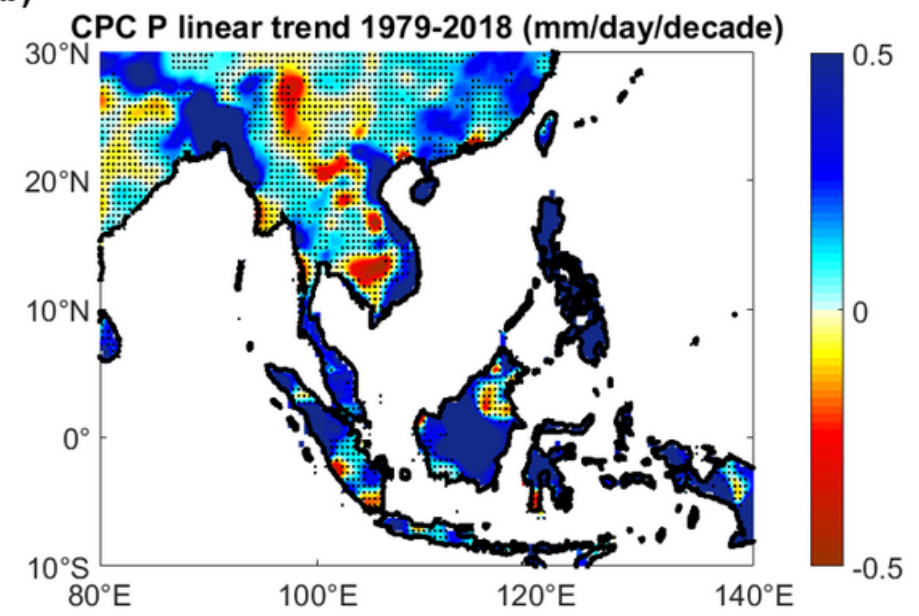

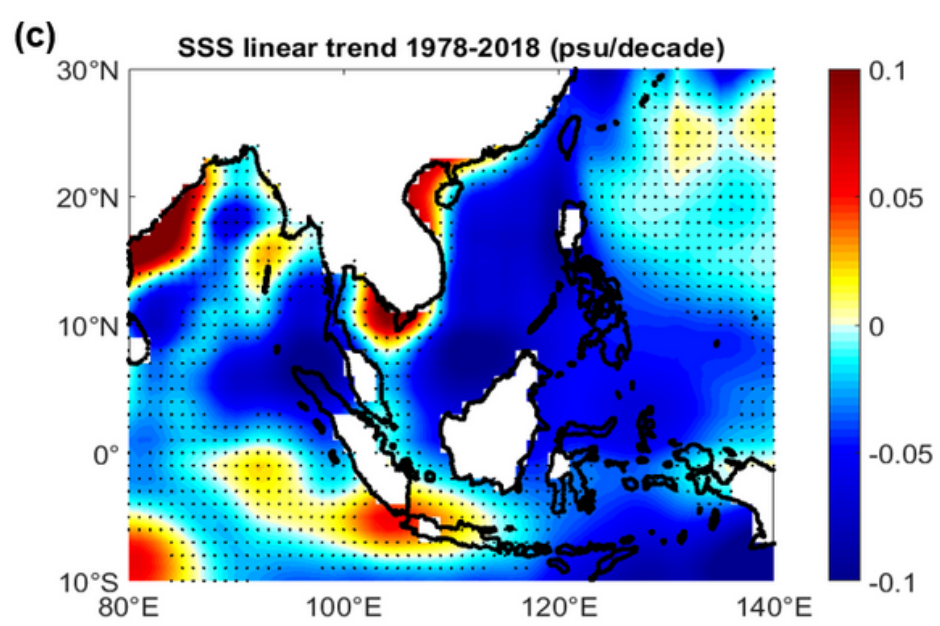

Figure 7

Linear trends over 1979-2018 in (a) GPCP Precipitation; (b) CPC Precipitation; (c) En4 Near Surface Salinity. Regions where the linear trend is not significant at the $95 \%$ confidence interval are stippled. 
(a)

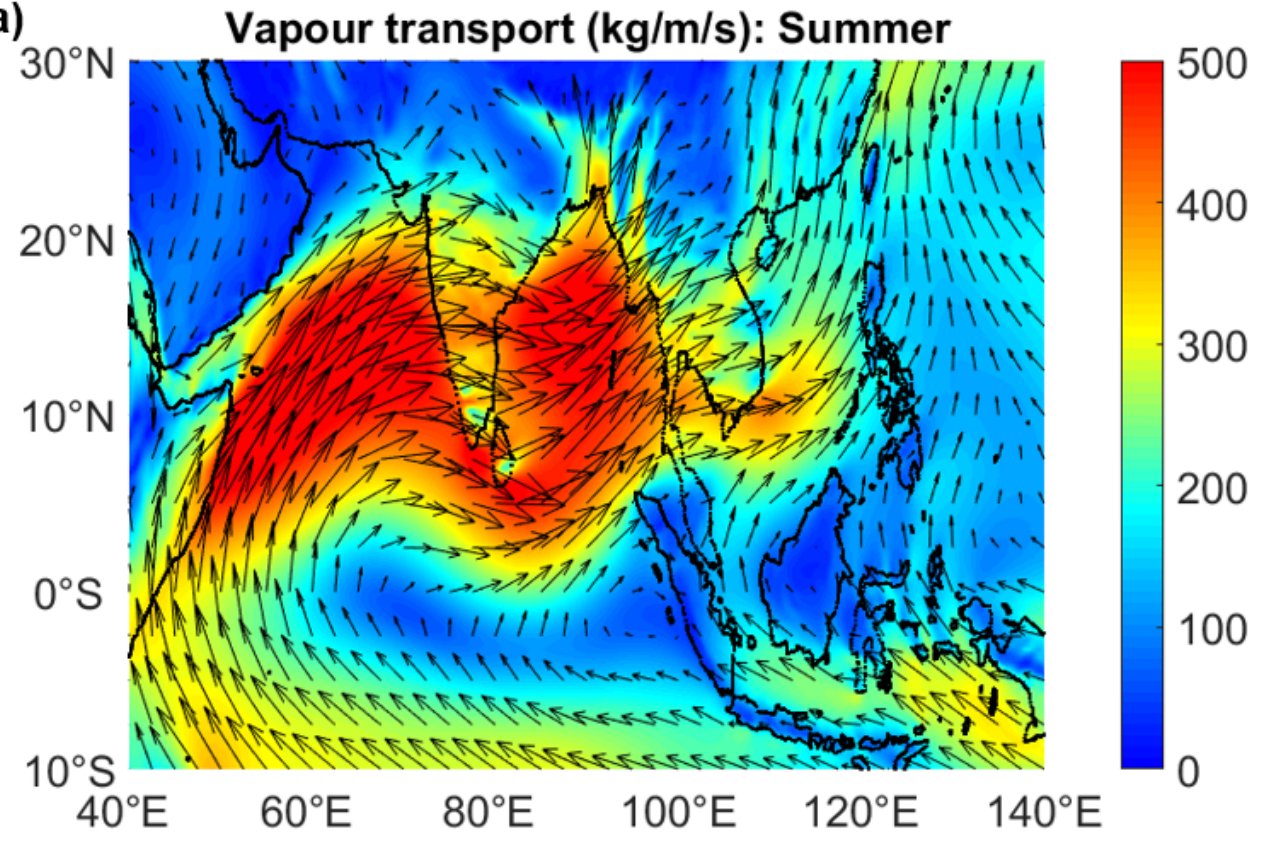

(b)

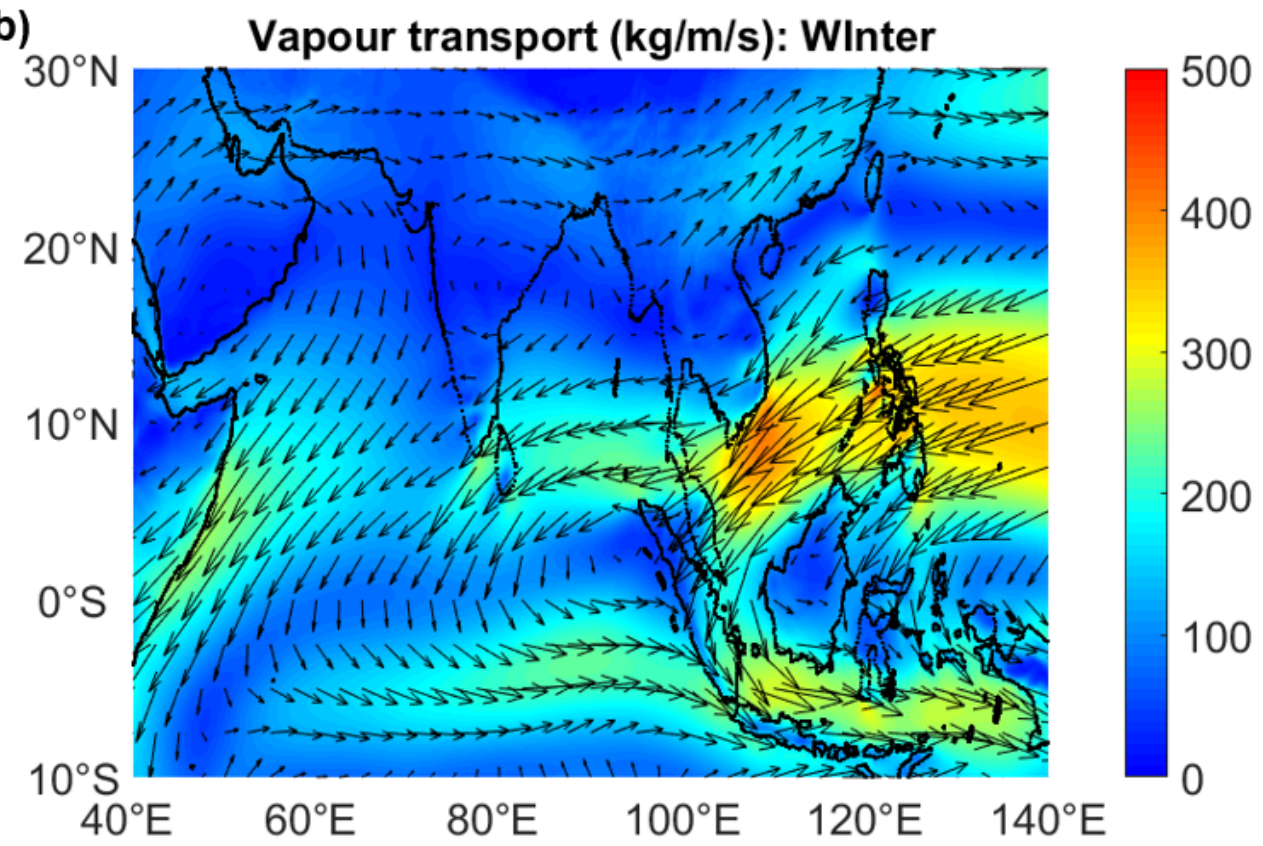

Figure 8

The climatology of vertically integrated atmospheric water vapour transport (vectors, kg m-1 s-1) for (a) summer (JJA) and (b) winter (DJF) during 1979-2018, based on the ERA5 monthly reanalysis data. Colour shading denotes the magnitude of the water vapour flux (kg m-1 s-1). 
(a) NCEP E 1950-2018 linear trend ( $\mathrm{mm} /$ day/dec.)

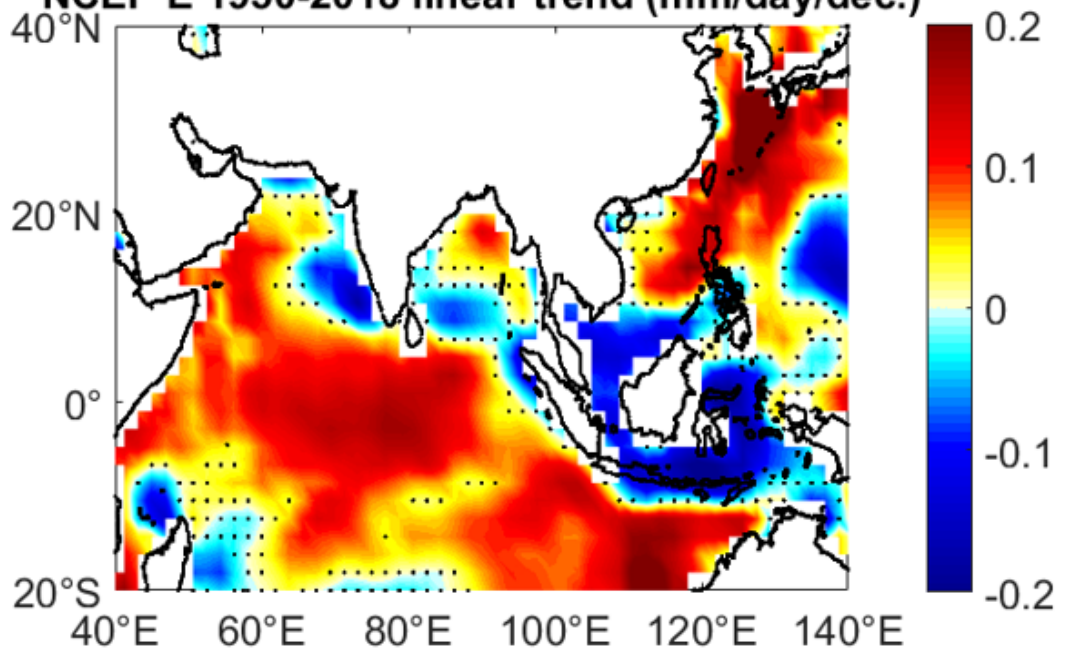

(b) OAFlux E 1958-2018 linear trend ( $\mathrm{mm} /$ day/dec.)

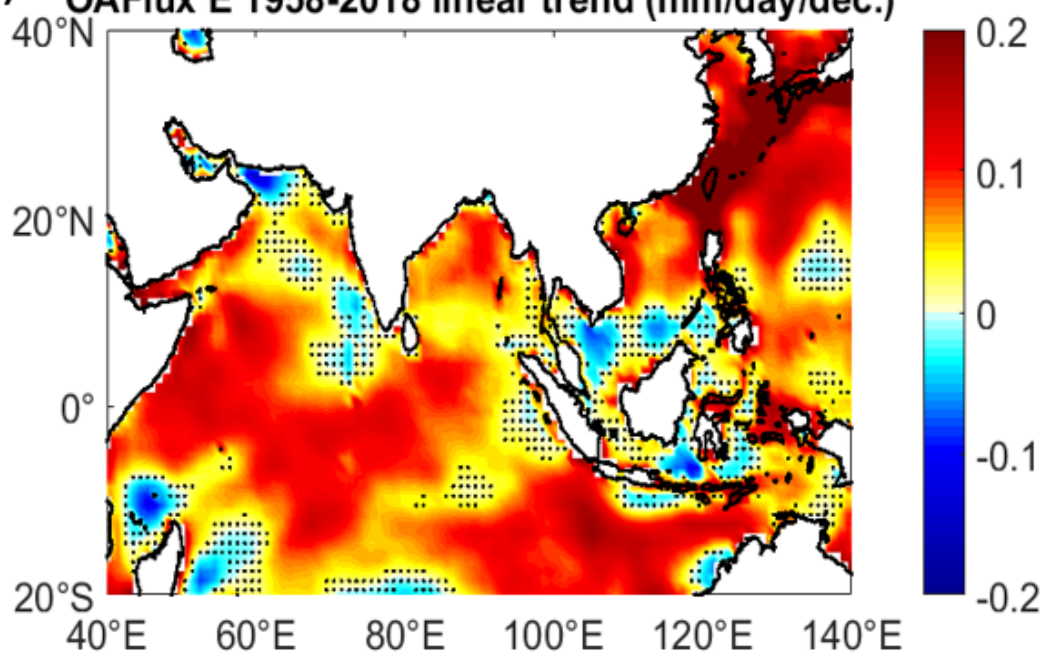

Figure 9

Linear trends in evaporation (mm/day/decade) from (a) OAFlux (1958-2018); (b) NCEP/NCAR (1950-2018). Regions where the linear trend is not significant at the $95 \%$ confidence interval are stippled. 
(a)

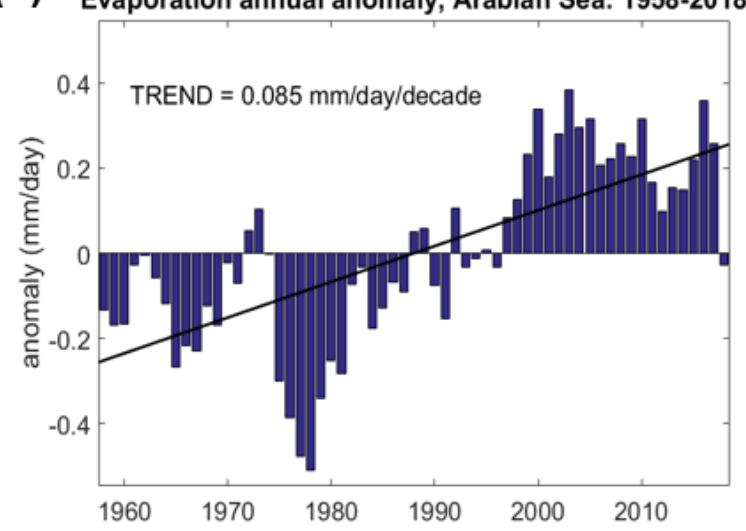

(b) Evaporation annual anomaly, Bay of Bengal: 1958-2018

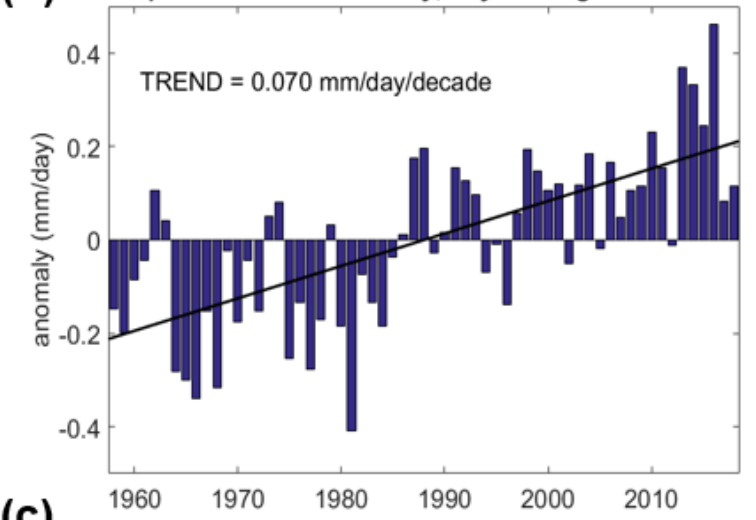

(c)

Evaporation annual anomaly, South China Sea: 1958-2018

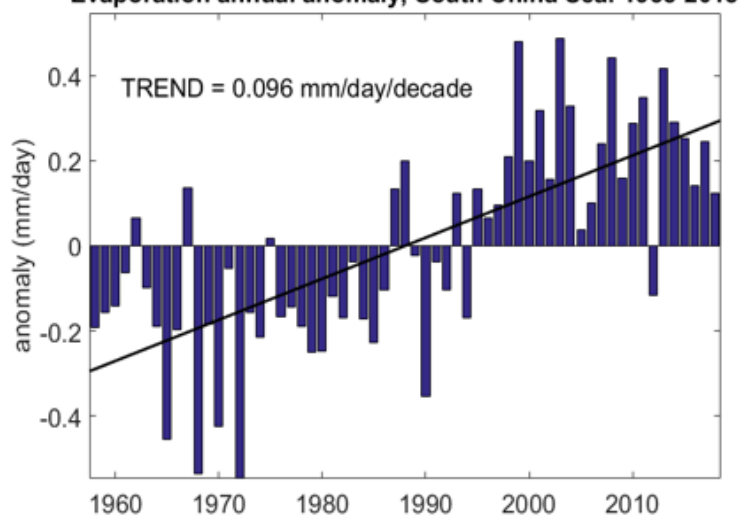

Figure 10

Area-averaged evaporation (OAFlux) annual anomalies over 1958-2018 for (a) Arabian Sea; (b) Bay of Bengal; (c) South China Sea. Linear trends (significant at the $99 \%$ confidence interval) are also depicted. 
(a)

$30^{\circ} \mathrm{N} \quad$ ERA5 E linear trend (1979-2018)

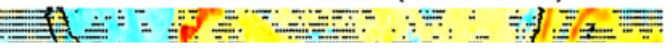

(b)

Water vapour Flux Magnitude trend (1979-2018) 0.5

\section{Figure 11}

ERA5 annual linear trends (1979-2018) in (a) Evaporation (mm/day/dec.); (b) Precipitation (mm/day/dec.); (c) Evaporation minus Precipitation ( $\mathrm{mm} / \mathrm{day} / \mathrm{dec}$.); (d) Magnitude of vertically integrated atmospheric water vapour transport (kg m-1 s-1/dec.). The climatological annual mean atmospheric water vapour transport (vectors, kg m-1 s-1) is also depicted. Regions where the linear trend is not significant at the $95 \%$ confidence interval are stippled. 
(a) Water vapour flux magnitude trend: Winter

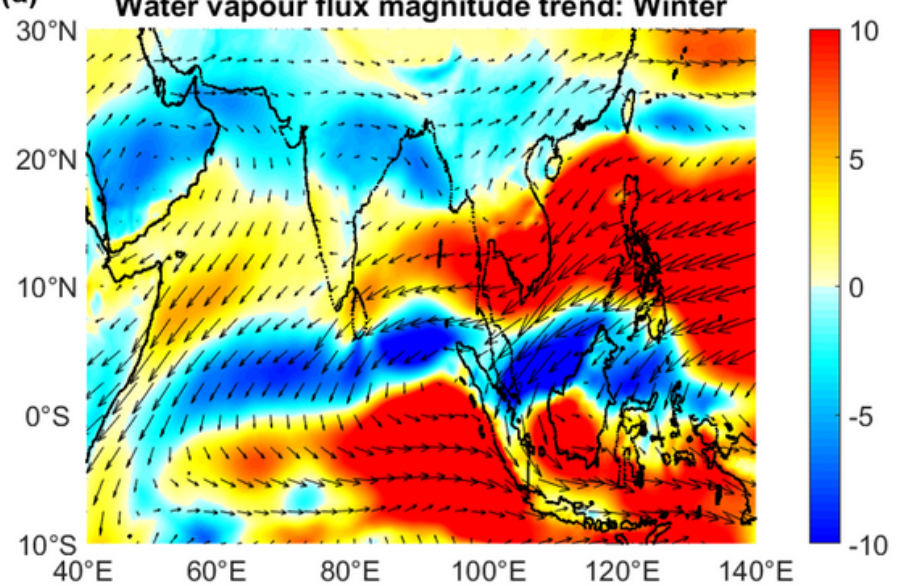

(c)

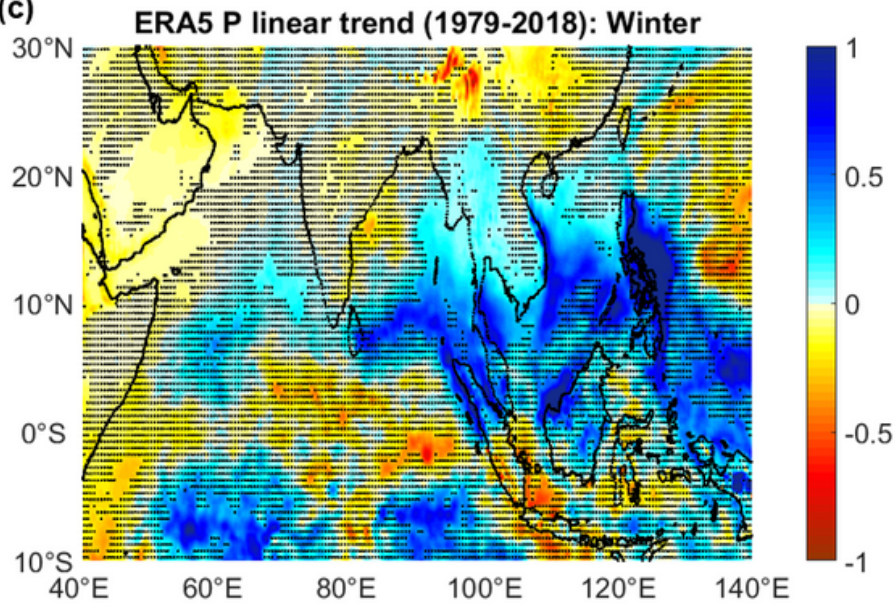

(b) Moist. Convergence linear trend (1979-2018): Winter

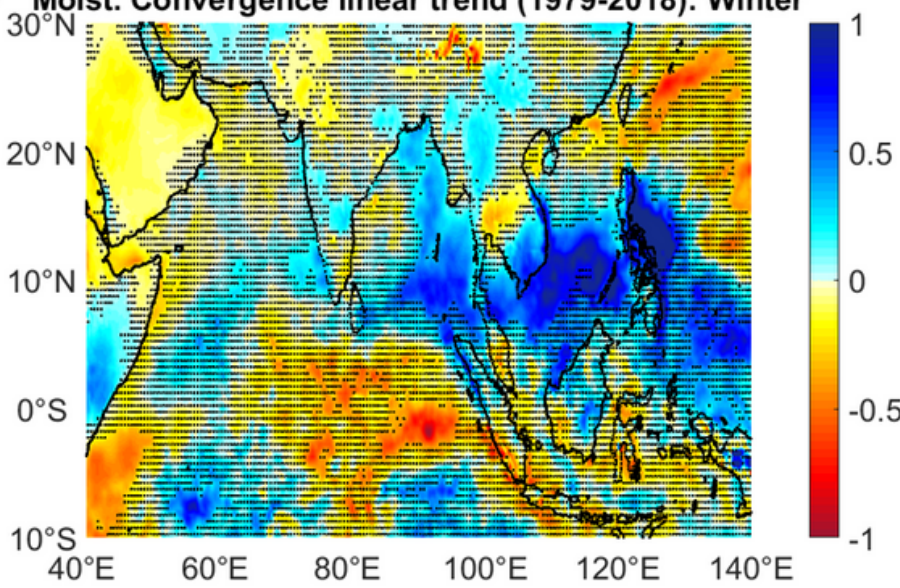

(d)

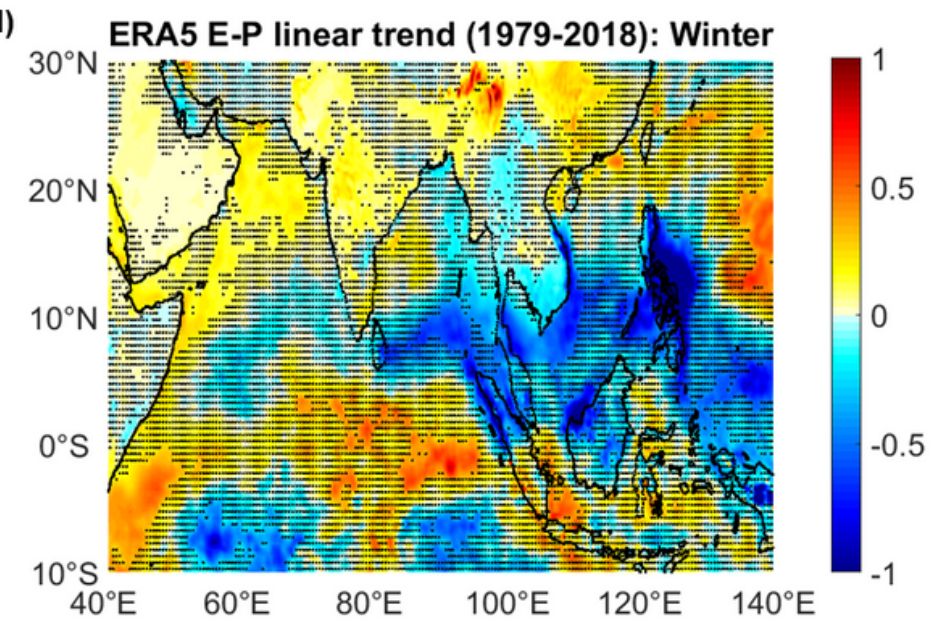

Figure 12

ERA5 summer (JJA) linear trends (1979-2018) in (a) Magnitude of vertically integrated atmospheric water vapour transport ( $\mathrm{kg} \mathrm{m}-1 \mathrm{~s}-1 / \mathrm{dec}$ ). The climatological summer mean atmospheric water vapour transport (vectors, kg m-1 s-1) is also depicted. (b) Moisture transport convergence (mm/day/dec.); (c) Precipitation (mm/day/dec.); (d) Evaporation minus Precipitation ( $\mathrm{mm} / \mathrm{day} / \mathrm{dec}$.). Regions where the linear trend is not significant at the $95 \%$ confidence interval are stippled. 
(a)

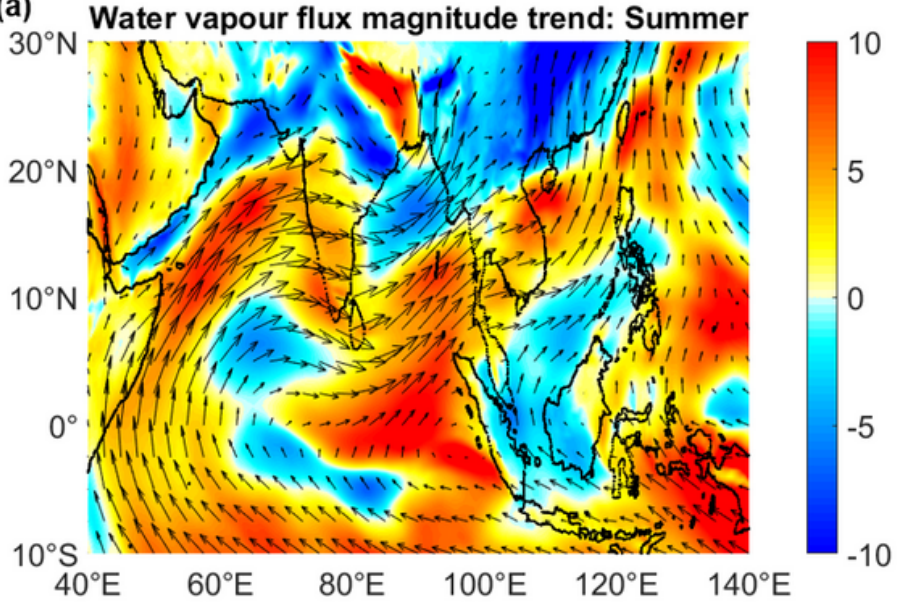

(c) ERA5 P linear trend (1979-2018): Summer

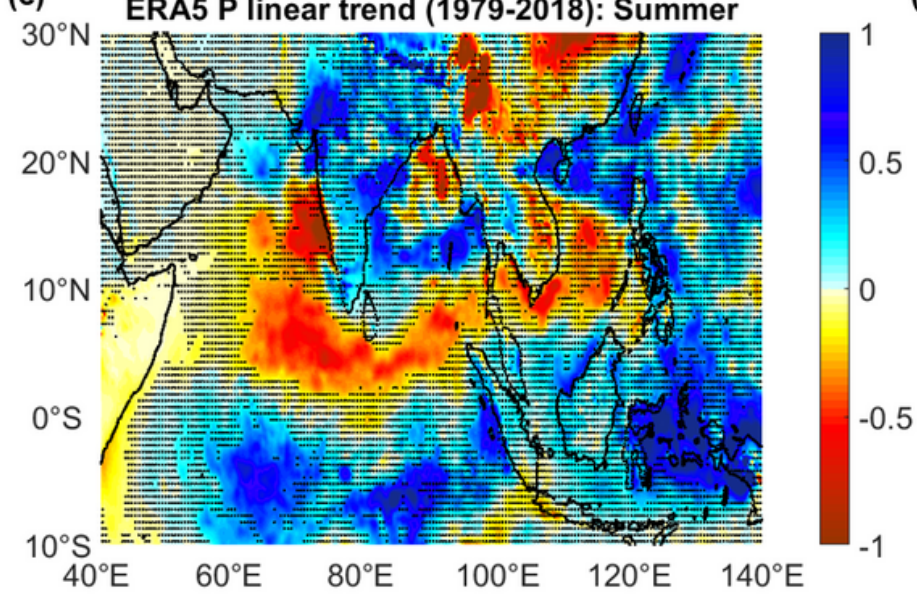

(b)

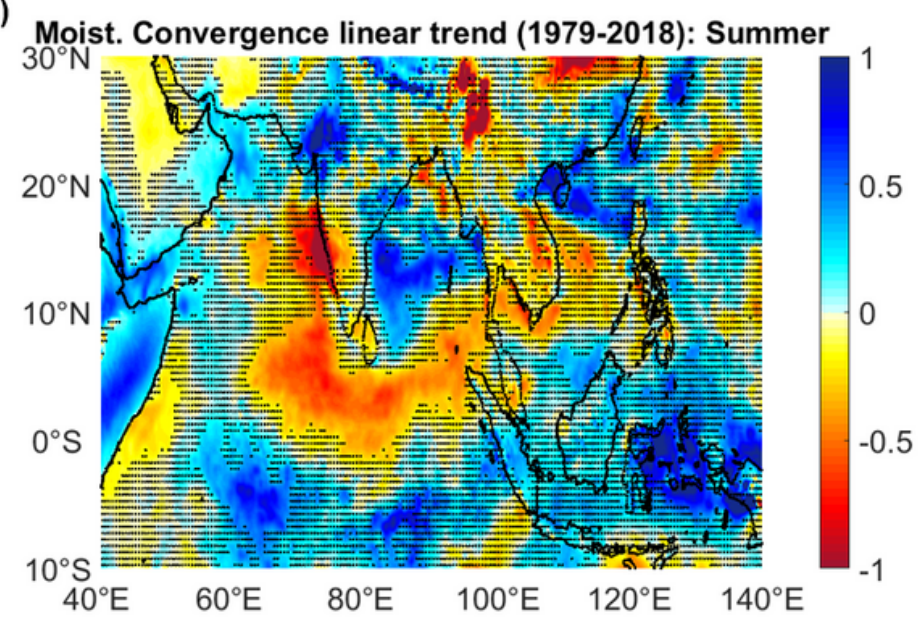

(d)

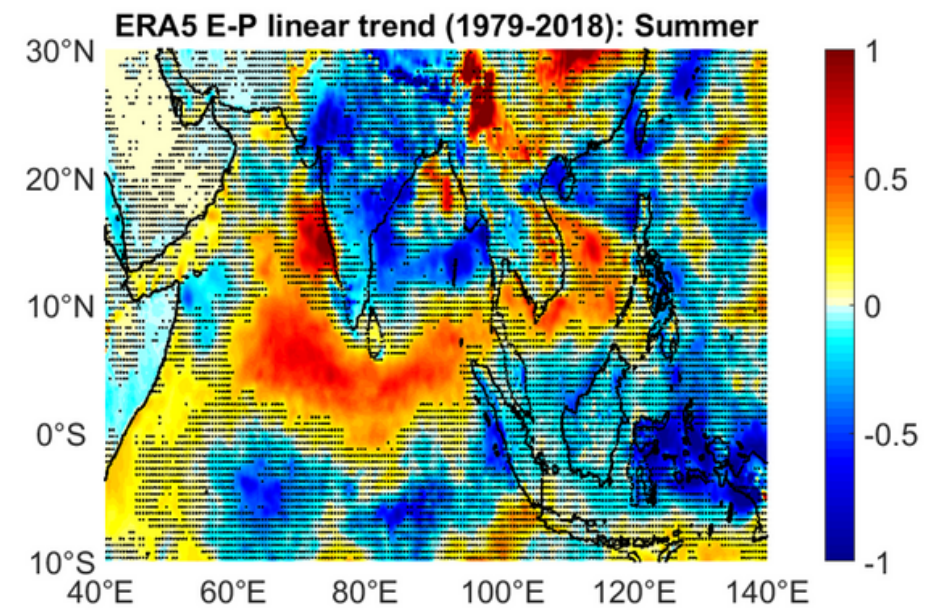

\section{Figure 13}

ERA5 winter (DJF) linear trends (1979-2018) in (a) Magnitude of vertically integrated atmospheric water vapour transport (kg m-1 s-1/dec). The climatological winter mean atmospheric water vapour transport (vectors, $\mathrm{kg} \mathrm{m}-1 \mathrm{~s}-1)$ is also depicted. b) Moisture transport convergence (mm/day/dec.); (c) Precipitation (mm/day/dec.); (d) Evaporation minus Precipitation (mm/day/dec.). Regions where the linear trend is not significant at the $95 \%$ confidence interval are stippled. 
(a)
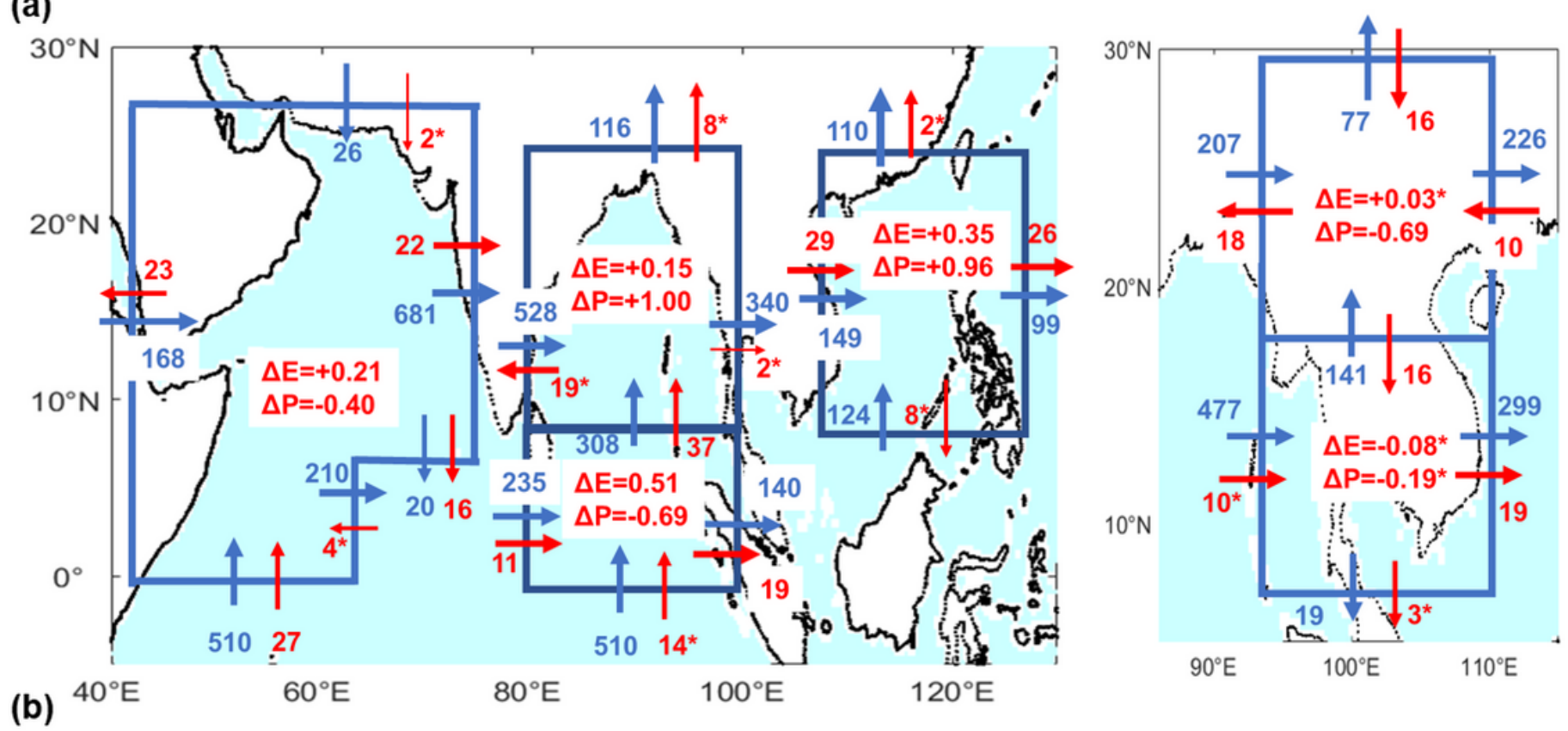

(b)
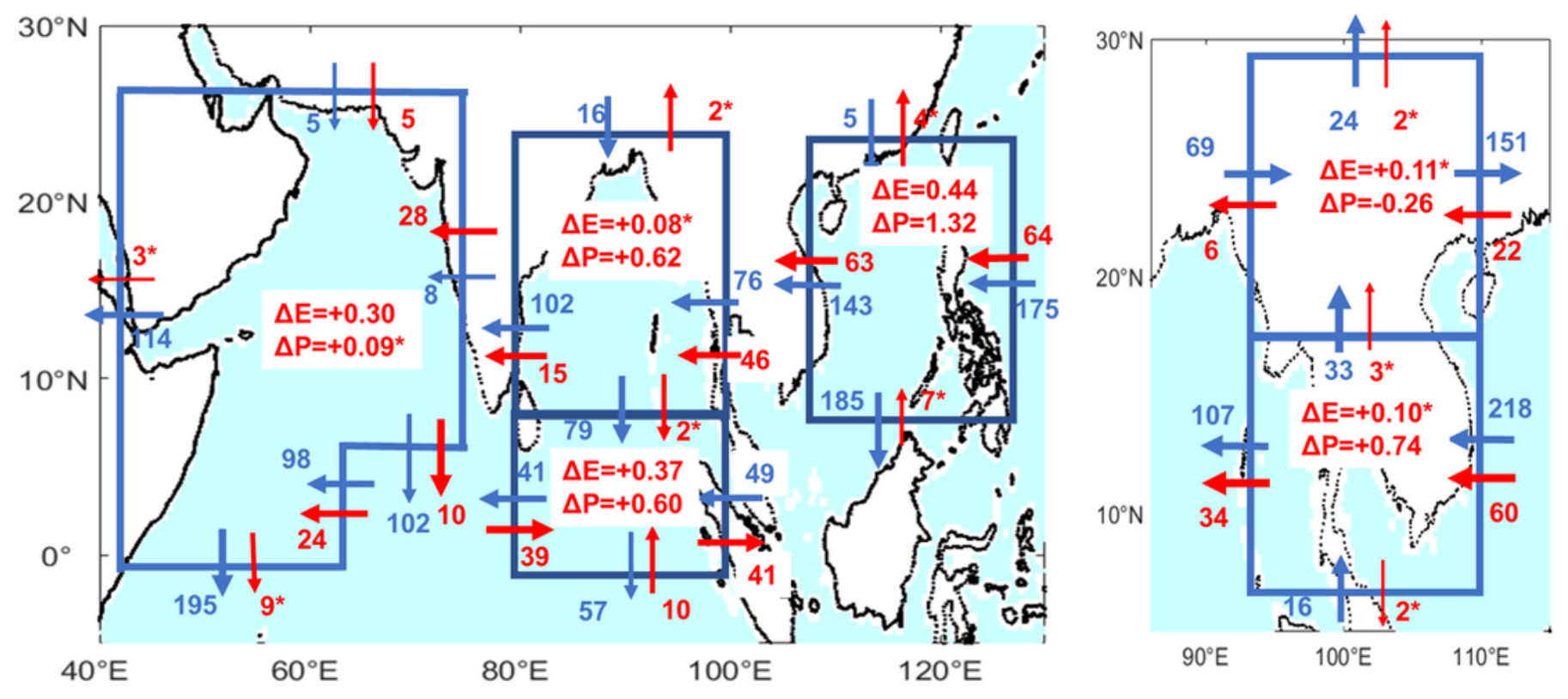

Figure 14

Linear trends (1979-2018) in area-averaged evaporation $\Delta \mathrm{E}(\mathrm{mm} /$ day/40 yrs) and precipitation $\Delta \mathrm{P}(\mathrm{mm} /$ day/40yrs) and atmospheric water vapour transport integrated along the zonal/meridional boundaries (in $106 \mathrm{~kg} / \mathrm{s} / 40 \mathrm{yrs}$ ) of four oceanic regions (Arabian Sea, Northeast equatorial region $\left(0-8^{\circ} \mathrm{N}\right)$, Bay of Bengal, and South China Sea) and for the south $\left(7-18^{\circ} \mathrm{N}\right)$ and north $\left(18-30^{\circ} \mathrm{N}\right)$ parts of the MSEA in (a) summer (JJA); and (b) winter (DJF), based on the ERA5 re-analysis. Blue and red vectors and accompanied values denote climatological mean and total change in transport direction and magnitude, respectively, over 1979-2018. Symbol ' $*$ ' denotes trends that are not statistically significant at the $95 \%$ confidence interval. 
(a)

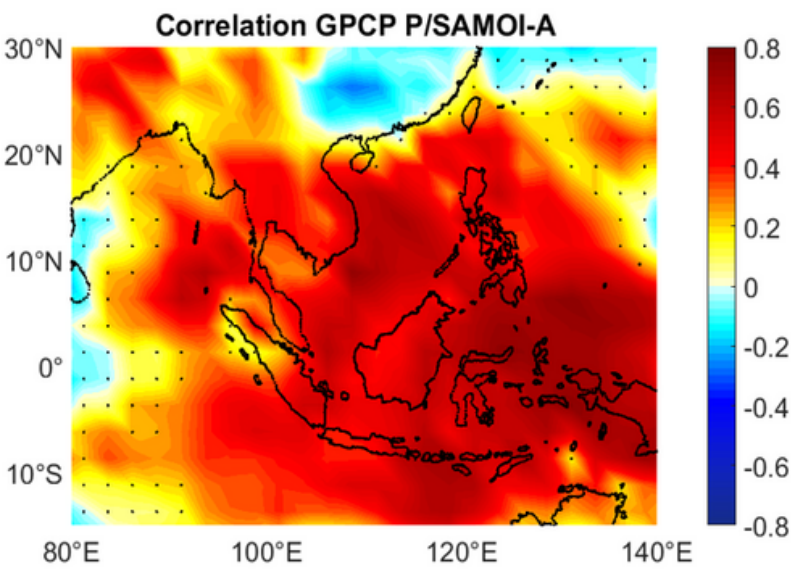

(c)

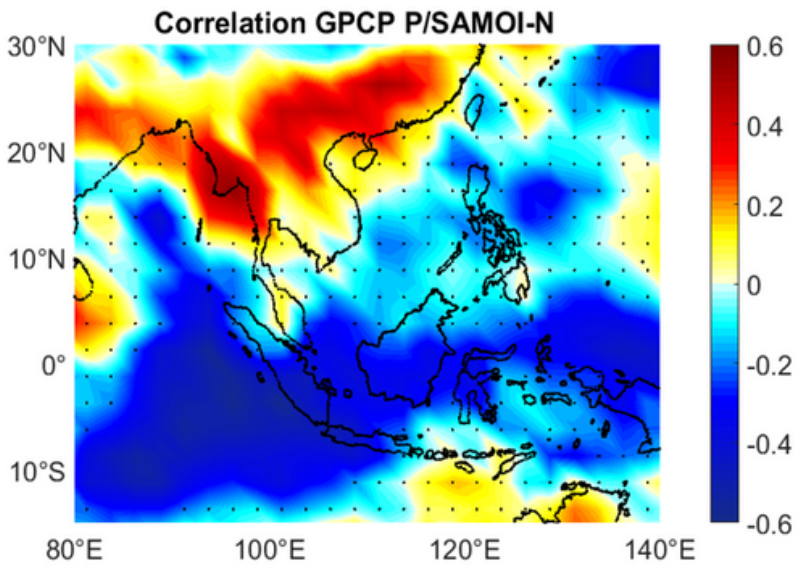

(b)

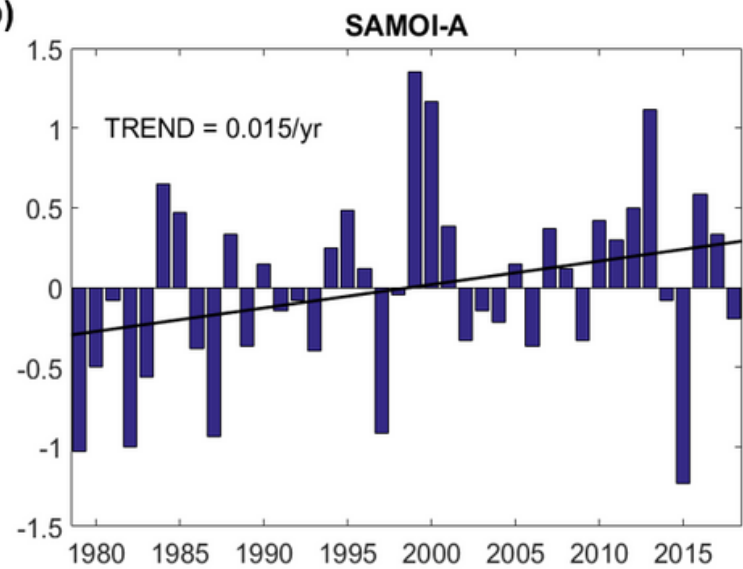

(d)

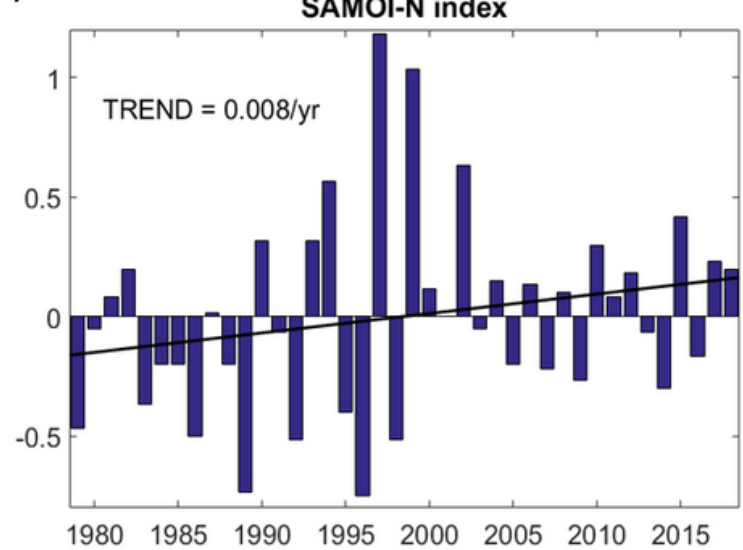

Figure 15

Correlation spatial patterns between annual mean precipitation (GPCP) and SAMOI-A and SAMOI-N index detrended timeseries (a, c). Regions where the correlation is not significant at the $95 \%$ confidence interval are stippled. SAMOI-A and SAMOI-N index annual timeseries over 1979-2018 (b, d). Linear trends (significant at the 90\% confidence interval) are also depicted. 
(a)

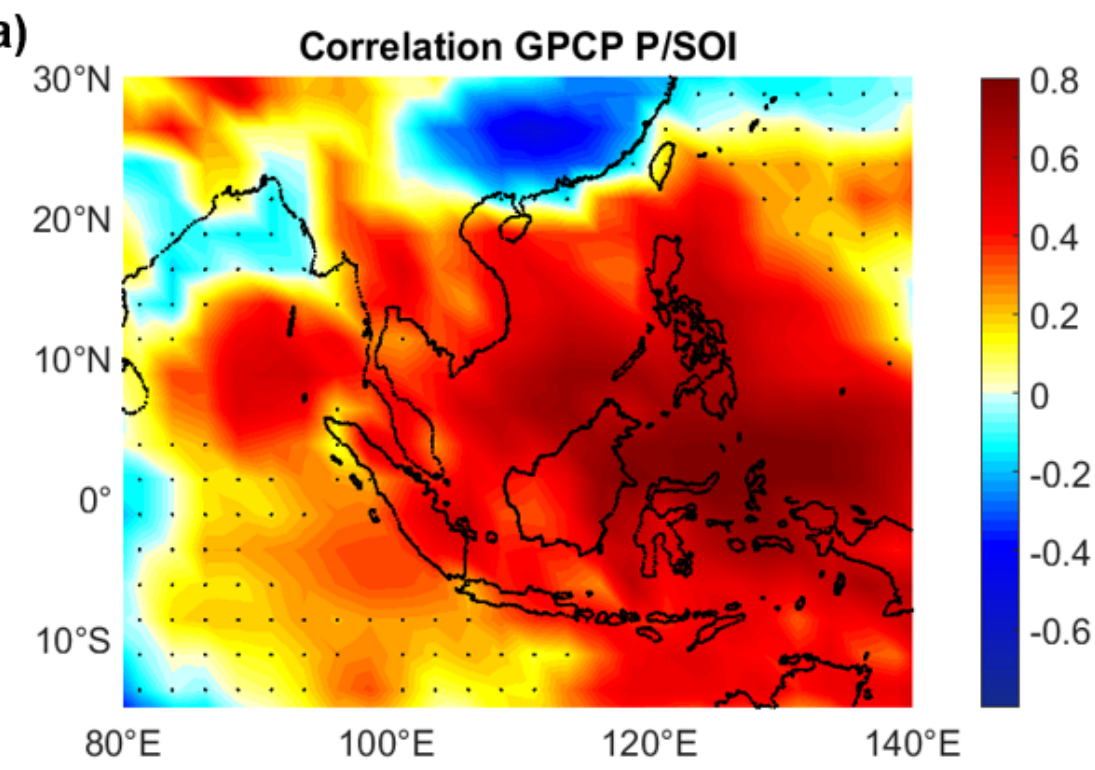

(b)

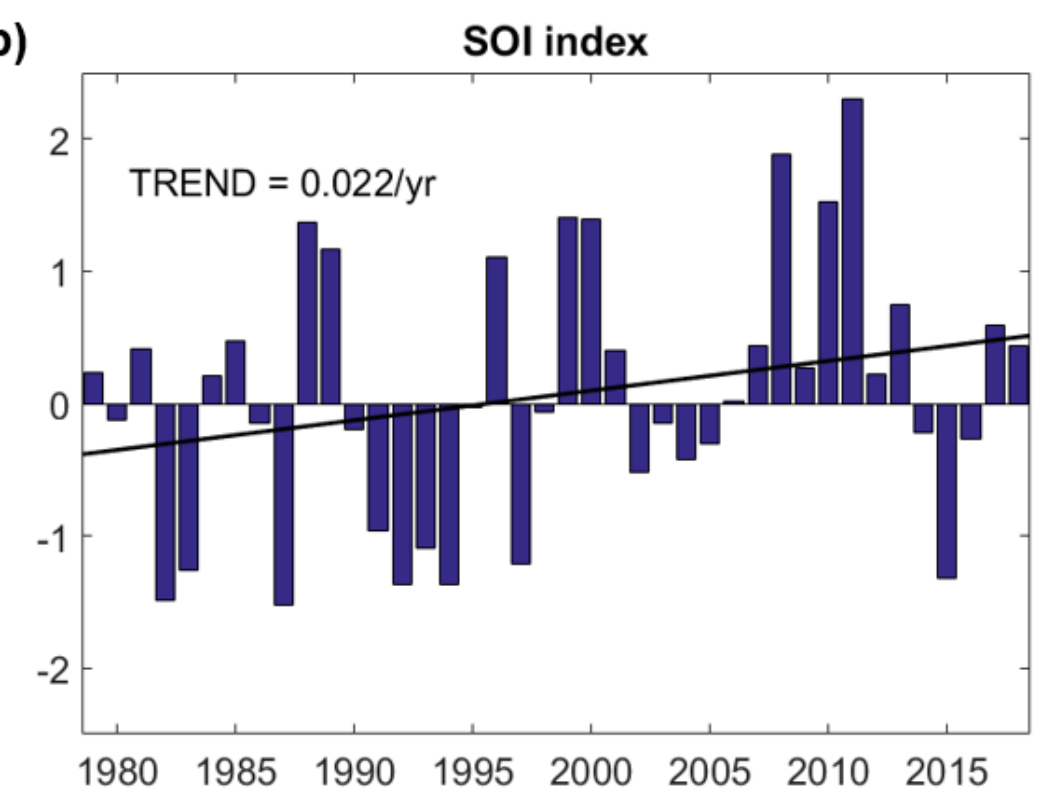

Figure 16

Correlation spatial pattern between annual mean precipitation (GPCP) and SOI (a). Regions where the correlation is not significant at the $95 \%$ confidence interval are stippled. SOI annual timeseries over 1979-2018 (b). The linear trend (significant at the $90 \%$ confidence interval) is also depicted. 
(a)

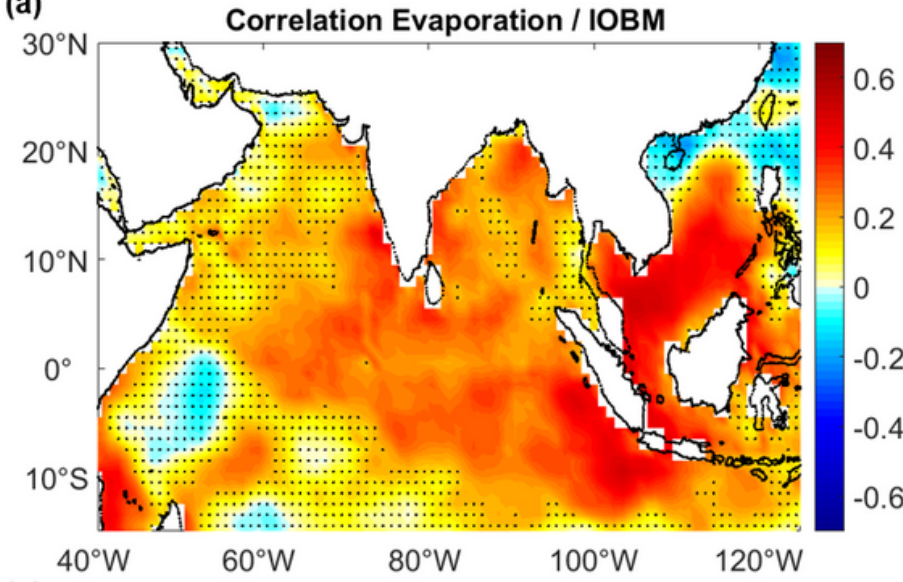

(c)

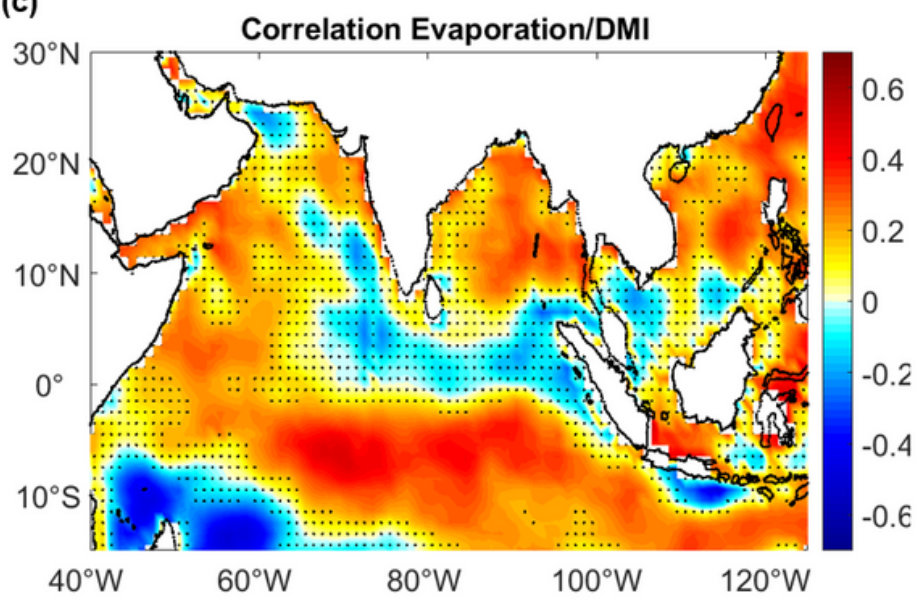

(b)

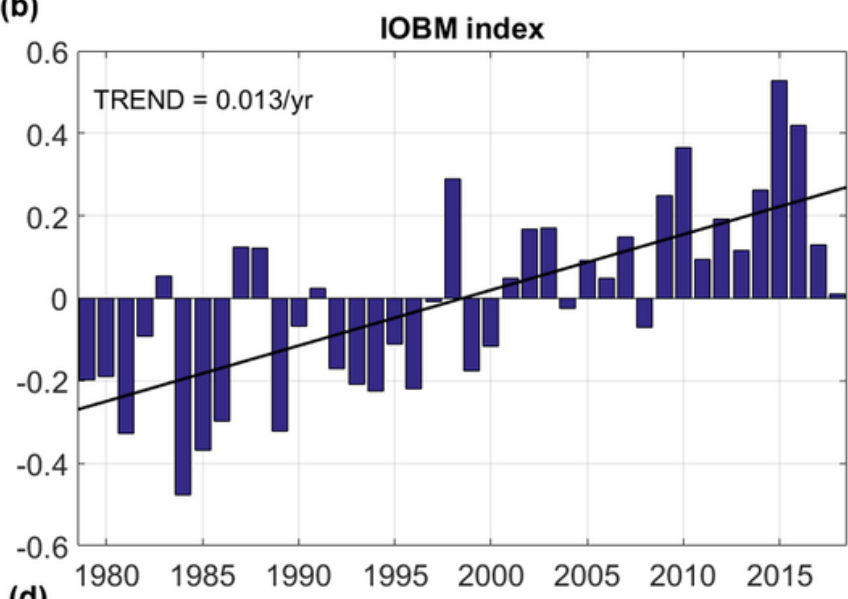

(d)

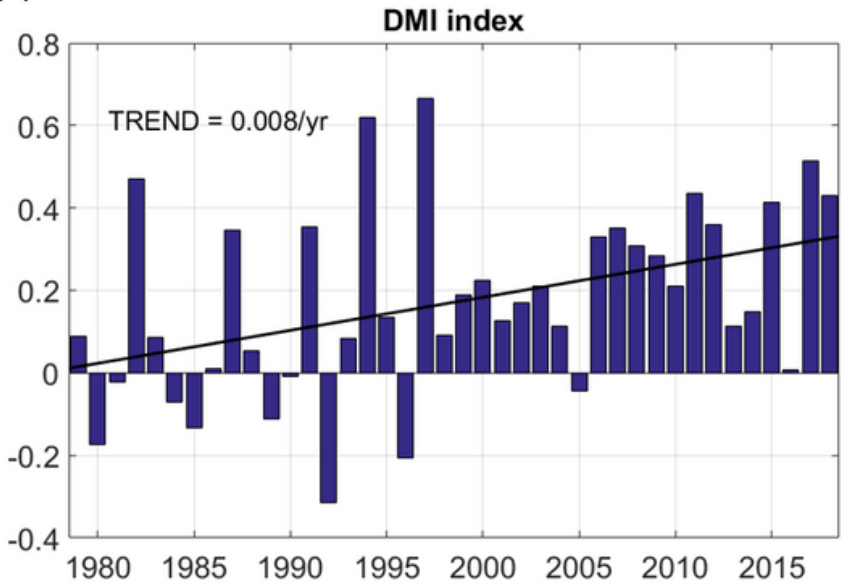

Figure 17

Correlation spatial patterns between annual mean evaporation (OAFlux) and (a) IOBM, (b) DMI. Regions where the correlation is not significant at the $95 \%$ confidence interval are stippled. Annual timeseries over 1979-2018 of (c) IOBM and (d) DMI. The linear trend (significant at the $90 \%$ confidence interval) is also depicted. 
(a)

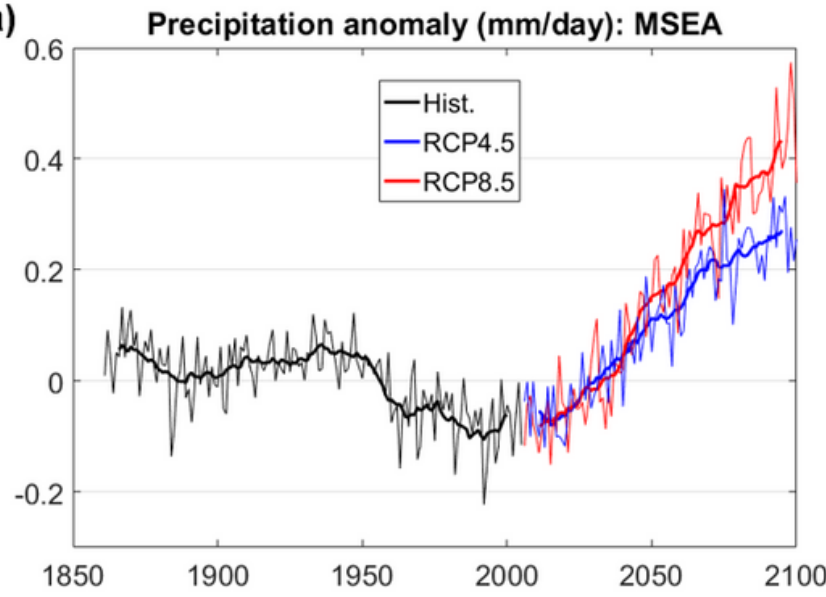

(c)

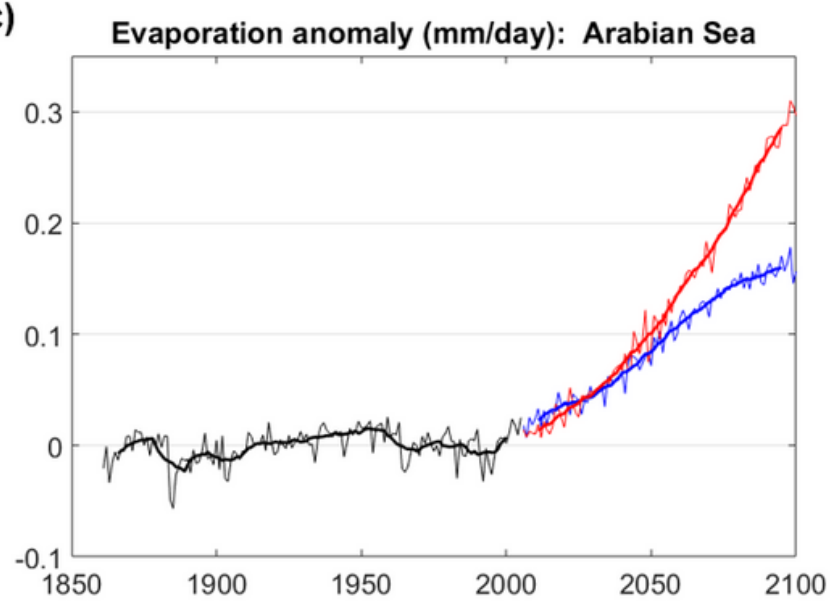

(b)

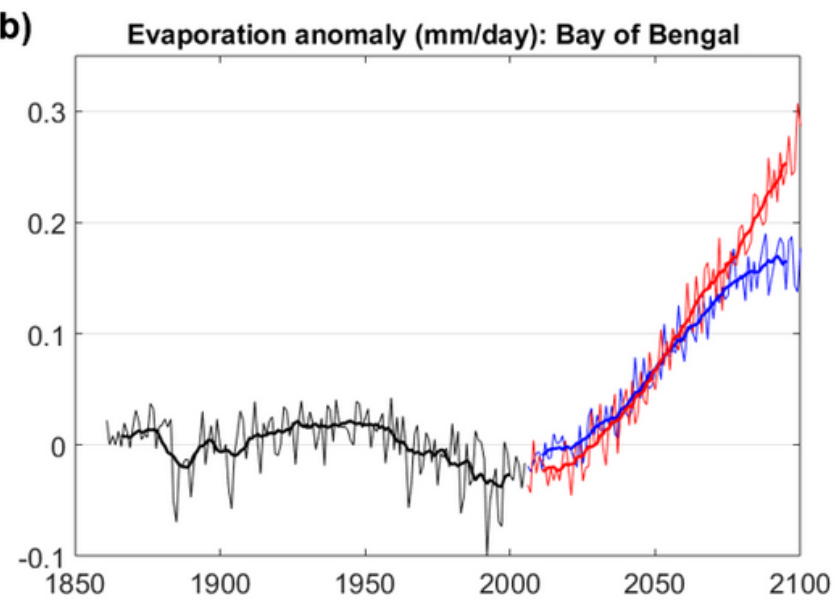

(d)

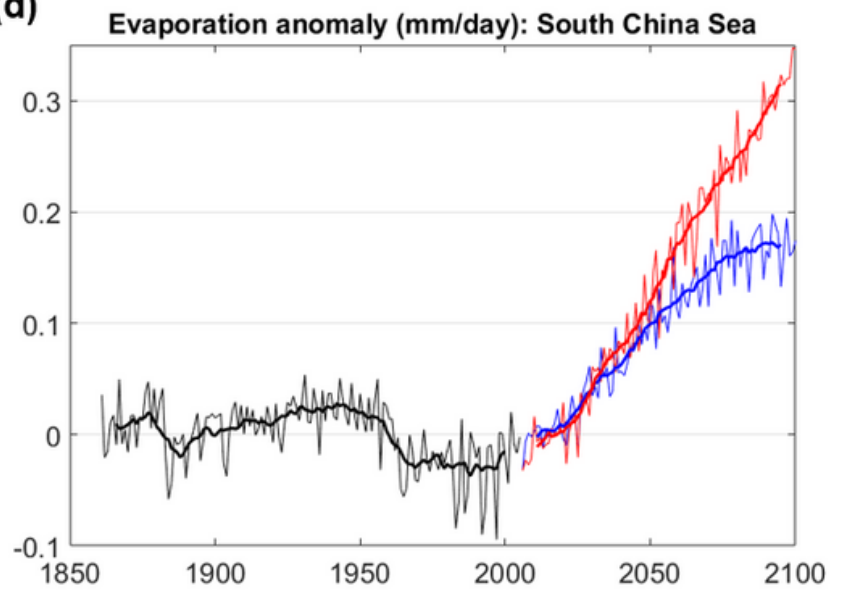

\section{Figure 18}

Annual timeseries of multi-model mean anomalies of land precipitation averaged over MSEA (a), and evaporation over the Arabian Sea (b), Bay of Bengal (c), and South China Sea (d) over 1860-2100 for historical (black), RCP4.5 (blue), and RCP8.5 (red) simulations. Thick solid lines depict 11-year running means. 